\title{
Legal Bargaining Theory's New "Prospecting" Agenda: It May Be Social Science, But Is It News?
}

\begin{abstract}
Robert J. Condlin*
In the good old days legal bargaining scholarship was based mostly on negotiator war stories exuberantly told. The social-scientific study of the subject did not begin in earnest until the nineteen-seventies. Since then, however, the literature of storytelling has gone into a pronounced eclipse and social-scientific study is now the principal scholarly game in town. This article questions the wisdom of this shift, almost seismic in its proportions, and argues that it is too soon to jump on the social science bandwagon. Discussion focuses on the uses made of the Prospect Theory of Daniel Kahneman and Amos Tversky and the Theory's central concept of Anchoring. Anchoring is the most thoroughly analyzed of the Prospect Theory concepts and difficulties encountered in incorporating it into legal bargaining theory will recur many times over in working with other parts of the Prospect Theory framework. It is an exemplary test case.
\end{abstract}

\section{INTRODUCTION}

Once upon a time most writing about bargaining practice ${ }^{1}$ was anecdotal, consisting of negotiator war stories colorfully and exuberantly told. Expert (or at least experienced) bargainers principally from the fields

\footnotetext{
* Professor of Law, University of Maryland School of Law. I am grateful to UM Foundation for financial support and to Sue McCarty for her customary excellent job of copy editing.

1. The article is about the set of skill moves and maneuvers lawyers use to influence outcomes in legal dispute negotiation, and not about the relationship between legal bargaining and personal transformation, deliberative democracy, or dispute system design. Discussions of the latter subjects, which are beginning to dominate in contemporary legal bargaining scholarship, seem to assume that bargaining skill issues are now all under control. I will question that assumption. For one of the best examples of the system design literature, and citations to much of the rest of it, see Amy J. Cohen, Dispute Systems Design, Neoliberalism, and the Problem of Scale, 14 HaRV. Negot. L. REV. 51, 51-54 (2009).

215
} 
of business, ${ }^{2}$ international relations, ${ }^{3}$ and law, ${ }^{4}$ regaled readers with descriptions of maneuvers that had helped gain the upper hand in negotiations with adversaries, joint venturers, and colleagues, sometimes famously. ${ }^{5} \quad$ Some of this writing was intelligent, insightful, and sophisticated, and some of it was fanciful, jumbled, and silly, but all of it was spirited and interesting. In a parallel universe, at around the same time, social psychologists, ${ }^{6}$ sociologists, ${ }^{7}$ economists, ${ }^{8}$ mathematicians, ${ }^{9}$ political scientists, ${ }^{10}$ and others ${ }^{11}$ began to write about bargaining in a more systematic and methodical manner. ${ }^{12}$ In thought experiments, puzzles, games, laboratory simulations, and surveys, some quite cleverly designed, these scholars measured the impact on bargaining outcome of a wide array of factors-personal, structural and substantive - that defined bargaining practice, and identified and described the moves and maneuvers that help one bargain effectively.

In legal bargaining scholarship in particular, there was a clear divide between these two types of work, with neither drawing on nor often even

2. E.g., Herb Cohen, You Can Negotiate Anything (1982); Chester L. Karrass, The Negotiating Game (1970). (1966)

3. E.g., ARthur Lall, Modern International Negotiation: Principles and Practice

4. E.g., John Ilich, The ART AND SKill of SucCesSFul Negotiation (1973); Gerard I. Nierenberg, Fundamentals of Negotiating (1973); Michael Meltsner \& Philip G. Schrag, Negotiating Tactics for Legal Services Lawyers, 7 Clearinghouse ReV. 259 (1973). For a more recent example of the genre, see James C. Freund, SMART Negotiating: How to MAKE Good DEALS IN THE REAL WORLD (1993).

5. E.g., Dean Acheson, Present at the Creation: My Years in the State DEPARTMENT 81-86, 276-84, 529-38 (1969) (describing the negotiation of the 1944 Bretton Woods agreement with Russia, the North Atlantic Treaty Organization, and the Korean Armistice, respectively).

6. E.g., Negotiations: Social-Psychological Perspectives (Daniel Druckman ed., 1977); DeAn G. Pruitt, Negotiation Behavior (1981); JefFrey Z. Rubin \& Bert R. Brown, The Social Psychology of Bargaining and Negotiation (1975); Richard E. Walton \& Robert B. McKersie, A Behavioral Theory of Labor Negotiations: An ANalysis of a SOCIAL INTERACTION SYSTEM (1965).

7. E.g., Samuel B. Bacharach \& Edward J. Lawler, Bargaining: Power, Tactics, AND OUTCOMES (1981); OTOMAR J. BARTOS, PROCESS AND OUTCOME OF NEGOTIATIONS (1974).

8. Thomas C. Schelling, The STRATEGy OF CONFLiCt (1960).

9. Howard RaifFa, The ART AND SCIENCE OF NegOtiation (1982).

10. BARgaining: Formal TheORIES OF Negotiation (Oran R. Young ed., 1975); I. William Zartman \& Maureen R. Berman, The Practical Negotiator (1983).

11. E.g., Communication and Negotiation (Linda L. Putnam \& Michael E. Roloff eds., 1992).

12. See Carrie Menkel-Meadow, Aha? Is Creativity Possible in Legal Problem Solving and Teachable in Legal Education?, 6 HARV. NEGOT. L. REV. 97, 97-98 (2001) (providing a concise history of this development).

216 
[Vol. 10: 2, 2010]

acknowledging the existence of the other. ${ }^{13}$ Over time, however, the two began to cross-pollinate, and ultimately to converge, first in the teaching materials and scholarly writing of the clinical law movement, ${ }^{14}$ and eventually in legal scholarship generally. The best early example of this convergence is the intellectually sophisticated but difficult set of materials on the lawyering process constructed by Gary Bellow and Bea Moulton in the early 1970 s. ${ }^{15}$ Drawing breathlessly on several diverse and complicated bodies of scholarship, Bellow and Moulton mixed social science findings about bargaining with expert practitioner insights to produce what might best be described as a legal version of a nineteenth century medical textbook; a serendipitous combination of literature and science fused together, tapestry-like, in annotated stories, case studies, and original notes. ${ }^{16}$ The book is still the high water mark in what might be thought of as the "public intellectual"17 approach to the study of legal bargaining.

The social-scientific study of bargaining by legal scholars began in earnest in the 1980s, a little over a decade after the first version of the Bellow and Moulton materials had begun to circulate. The work of Gerald

13. Chester Karrass is an exception. See KarRass, supra note 2. An experienced aerospace industry negotiator, he peppered his book The Negotiating Game with examples from his practice, but also grounded the discussion in sociological theories and methods. The book is based on his Ph.D. thesis. See Chester L. Karrass, A Study of the Relationship of Negotiator Skill and Power as Determinants of Negotiation Outcome (Aug. 1968) (unpublished Ph.D. dissertation, University of Southern California).

14. See Robert Stevens, Law School: Legal Education in America from the 1850S TO THE 1980s, 214-16, 229-30, 240-41 (1983) (describing the development of clinical legal education); M.H. Hoeflich, Plus Ça Change, Plus C'Est la MÊME Chose: The InTEgration of Theory and Practice in Legal Education (1993), reprinted in 2 The History of Legal EDUCATION IN THE UNITED STATES: COMMENTARIES AND PRIMARY SOURCES 861 (Steve Sheppard ed., 1999).

15. The materials ultimately were published by Foundation Press in the late 1970s. See GARY Bellow \& Bea Moulton, The LAWYering Process: Materials for CliniCAl INSTRUCTION IN ADVOCACY (1978). They were then republished in separate, skill-specific paperback editions in the early 1980s. See, e.g., Gary Bellow \& Bea Moulton, The Lawyering Process: Negotiation (1981); Gary Bellow \& Bea Moulton, The Lawyering Process: Ethics and Professional RESPONSIBILITY (1981).

16. See Bellow AND Moulton, supra note 15.

17. See Richard A. Posner, Public Intellectuals: A Study of Decline (2001); The Future of the Public Intellectual: Panel Discussion, THE NATION, Feb. 12, 2001, at 25, available at http://www.thenation.com/doc/20010212/forum; Richard C. Lewontin, The Triumph of Stephen Jay Gould, in N.Y. REV. OF BOOKS, Feb. 14, 2008, at 39 (defining "public intellectual"); Alan Lightman, The Role of the Public Intellectual, MIT COMM. FORUM, Jan. 5, 2000, available at http://web.mit.edu/comm-forum/papers/lightman.html. 
Williams and his colleagues at Brigham Young University ${ }^{18}$ usually is given as the starting point, though Cornelius Peck published a casebook on legal negotiation a few years earlier, ${ }^{19}$ Harry Edwards and Jim White published another one at about the same time, ${ }^{20}$ and both of these books drew extensively on social science research. ${ }^{21}$ Perhaps spurred on by the "two cultures" debate at Cambridge in the $1950 \mathrm{~s},{ }^{22}$ law study, like humanities education generally, envied its scientific relations. ${ }^{23}$ Science provided objectivity, precision, parsimonious expression, elegance, and cumulative learning, while humanities offered only indeterminacy, personal opinion, ad hoc perspective, reasonable disagreement, and situational truth in return. ${ }^{24}$

18. Gerald R. Williams, Legal Negotiation AND SETtLement (1983).

19. Cornelius J. PeCK, CASES AND Materials on Negotiation (1972).

20. Harry T. Edwards \& James J. White, The Lawyer as a Negotiator: Problems, READINGS AND MATERIALS (1977).

21. Richard Walton and Robert McKersie did their highly regarded work even earlier. They were not legal academics, but because they studied labor relations, their writing overlapped with legal scholarship to a considerable extent. See WALTON \& MCKERSIE, supra note 6.

22. Robert J. Condlin, "What's Really Going On?" A Study of Lawyer and Scientist InterDisciplinary Discourse, 25 RUTGERS COMPUTER \& TECH. L.J. 181, 181-206 (1999) (describing the "two cultures" debate). See Jerome Kagan, The Three Cultures: Natural Sciences, Social SCIENCES AND THE HUMANITIES IN THE $21^{\text {sT }}$ CENTURY (2009) (explaining that there are now three cultures).

23. See STEVENS, supra note 14, at 131-41 (showing how legal education interest in the social sciences predates the "two cultures" debate by several decades).

24. Some scientists also criticized humanities thinkers for being unduly sympathetic to, or at least not sufficiently critical of, the rise of fascism and National Socialism. See C.P. SNOw, THE Two Cultures: A SECOND LOOK 7 (1993) ("“N]ine out of ten of those who have dominated literary sensibility in our time [were] ... not only politically silly, but politically wicked.... [T] he influence of all they represent [brought] Auschwitz that much nearer."). The difference between scientific and humanities based thinking can be overstated, of course. Science can be partisan, even extremely so. Recently, for example, David Card, a former winner of the John Bates Clark Prize, discovered that studies finding the minimum wage to have a statistically significant disemployment effect were overrepresented in the scholarly literature. See Douglas Clement, Interview with David Card, ThE ReGion, Dec. 2006, http://www.minneapolisfed.org/pubs/region/06-12/card.cfm (last visited Nov. 14, 2009). He concluded that there were rewards within the field of economics for producing scholarship that confirmed the idea that the minimum wage caused unemployment and punishment for scholarship that found otherwise. See id. He stopped writing about this topic, however, when "a lot of his friends ... became very angry [at] or disappointed [in him because] ... they thought that in publishing [his] work [he was] being [a] traitor to the cause of economics as a whole." Id. See also Gregory Mitchell, Taking Behavioralism Too Seriously? The Unwarranted Pessimism of the New Behavioral Analysis of Law, 43 WM. \& MARY L. REV. 1907, 2018 (2002) [hereinafter Mitchell, Taking Behavioralism Too Seriously?] ("[M]arket forces may be driving [behavioral decision theorists] to puffery and exaggeration. ... [B]lanket irrationality probably sells better than a nuanced, contextualized picture of human behavior full of individual ... differences in rationality and lacking in cognitive universals."). Humanities based thinking also can be objective. See Robert A. Prentice, Chicago Man, K-T Man, and the Future of Behavioral Law and Economics, 56 VAND. L. ReV. 1663, 1719 (2003) [hereinafter Prentice, Chicago Man] ("Research results in 218 
[Vol. 10: 2, 2010]

Science also had a positive, prescriptive agenda for how to behave effectively, not just a critical one for describing how behavior had fallen short. ${ }^{25}$ To be scientific was thought to be first among equals in the academy and this had an irresistible allure for legal scholars who, at that time, almost obsessively doubted the legitimacy of their place in the academy. ${ }^{26}$

Initially, legal bargaining theory borrowed heavily from psychiatric, psychological, and political science models (and, to a lesser extent, those of economics, game theory, and social choice theory), where the systematic study of social behavior had a longer and more developed history. ${ }^{27}$ But then, as in the writings of Williams and his colleagues, it began to produce original work grounded in the direct study of lawyer bargainers. ${ }^{28}$ This shift

psychology are roughly as consistent as those in physics, and as reliable as many prominent findings in medical science.") (citations omitted).

25. This point usually is illustrated by comparing Law \& Economics scholarship with that of Critical Legal Studies. See, e.g., Richard A. Posner, Social Norms, Social Meaning, and Economic Analysis of Law: A Comment, 27 J. LEGAL STUD. 553, 565 (1998) (describing law and economics as a "progressive" program and critical legal studies as a "degenerate" one).

26. See Thomas F. Bergin, The Law Teacher: A Man Divided Against Himself, 54 VA. L. REv. 637 (1968) (providing the best illustration). Science envy may persist among legal bargaining scholars to the present day. The newest ABA-sponsored negotiation manual, for example, describes itself as engaged in "science." See BARRy GOldman, The SCIENCE OF SETTLEMENT: IdEAS FOR NEGOTIATORS (2008). Jeffrey Rachlinski also is emphatic about Behavioral Decision Theory's claim to being scientific. See Jeffrey J. Rachlinski, The "New" Law and Psychology: A Reply to Critics, Skeptics, and Cautious Supporters, 85 CORNELl L. REV. 739, 750 (2000) ("The field [of Behavioral Decision Theory] is modeled after successful research programs in the study of perception and memory.... [Its] ultimate goal ... is ... to produce an accurate account of human judgment and decision making.") (citing Daniel Kahneman \& Amos Tversky, On the Reality of Cognitive Illusions, 103 PSYCHOL. REV. 582 (1996)). But see generally Joseph Vining, The Resilience of Law, in LAW AND DEMOCRACY IN THE EMPIRE OF FORCE (H. Jefferson Powell \& James Boyd White eds., forthcoming 2009), available at http://ssrn.com/abstract $=1147665$ (describing why law is not and cannot be a social science).

27. See, e.g., ANDrew S. WATSON, THE LAWYer IN THE INTERVIEWING AND CounSELing Process (1976); Robert SAMuel Redmount, Legal InTERVIEWING AND COUNSEling (1980); Robert S. Redmount, The Transactional Emphasis in Legal Education, 28 J. LEGAL EdUC. 253 (1974).

28. See generally WILLIAMS, supra note 18. Williams and his colleagues published the results of a follow-up study in 1991. Id. See also Lloyd Burton et al., Feminist Theory, Professional Ethics, and Gender-Related Distinctions in Attorney Negotiating Styles, 1991 J. DisP. RESOL. 199 (1991) (providing follow-up research on feminist perspective). Andrea Kupfer Schneider has updated Williams' work and conducted extensive empirical research of her own. See Andrea Kupfer Schneider, Shattering Negotiation Myths: Empirical Evidence on the Effectiveness of Negotiation Style, 7 HaRv. NeGOT. L. REV. 143, 148 (2002); Andrea Kupfer Schneider \& Nancy Mills, What Family Lawyers Are Really Doing When They Negotiate, 44 FAM. CT. REV. 612 (2006). I discuss Williams and Schneider's work at length in Robert J. Condlin, "Every Day and in Every Way We 219 
from anecdote to science is perhaps best reflected in the changing makeup of the Wiggins and Lowry reader, ${ }^{29}$ the principal legal negotiation anthology. Entries in the book's second edition, taken in larger measure from social scientific (and ersatz social scientific) scholarship, replaced or supplemented the practitioner contributions that predominated in the first edition, to give the anthology a new and decidedly scientific look. At the same time, the principal scholarly journals in the field began to publish social science based bargaining scholarship in increasing measure. ${ }^{30}$ The literature of storytelling and anecdote did not disappear altogether, of course, ${ }^{31}$ but it went into a pronounced eclipse, so that often it appeared that the social-scientific study of legal bargaining was the only scholarly game in town. ${ }^{32}$ The wisdom of that shift in emphasis, almost seismic in its proportions, is the subject of this article.

Social science writing about bargaining is too voluminous, varied, and complex to examine in its entirety, so I will limit my discussion to a part of it that, for the moment at least, seems to hold great fascination for legal

Are All Becoming Meta and Meta," or How Communitarian Bargaining Theory Conquered the World (of Bargaining Theory), 23 OHIO ST. J. ON DisP. ReSOL. 231, 278-89 (2008). The Williams/Schneider research is about lawyer bargainers more than legal bargaining, since it is based on lawyers' self-reports about how they bargain rather than direct observation of bargaining behavior.

29. Charles B. Wiggins \& L. Randolph Lowry, Negotiation and Settlement ADVOCACY: A BOOK OF READINGS (2d ed. 2005). The earlier edition of the book was published in 1997. The Negotiator's Fieldbook, a new ABA deskbook on negotiation, has the same scientific emphasis. See ABA Section of Dispute Resolution, The Negotiator's Fieldbook (Andrea Kupfer Schneider \& Christopher Honeyman eds., 2006).

30. Journals in social psychology, economics, organizational theory, and related fields published articles on bargaining long before law journals, of course, but little of this work made its way into legal bargaining scholarship. See, e.g., Issue on Negotiation: Behavioral Perspectives, 27 AM. BEHAV. SCIENTIST 131-279 (1983).

31. Some commentators combine the two approaches. See, e.g., Ian Weinstein, Don't Believe Everything You Think: Cognitive Bias in Legal Decision Making, 9 ClinICAL L. ReV. 783 (2003) (using Behavioral Decision Theory concepts to analyze bargaining scenarios from real life law practice); G. Richard Shell, Bargaining fOR AdVAntage: Negotiation Strategies for REASONABle PeOPLE (2d ed. 2006) (using social psychology concepts to analyze real world business negotiations).

32. But see Deepak Malhotra \& Max H. Bazerman, Psychological Influence in Negotiation: An Introduction Long Overdue, 34 J. MGMT. 509-31 (2008) (describing the surprisingly "limited extent to which social influence research has penetrated the field of negotiation"). It is not unusual for ideas to dominate a field of study when they are first introduced, at least for a short time. See ClifFord GeERTZ, The InTERPRETAtion OF Cultures 3 (1973) ("[C]ertain ideas burst upon the intellectual landscape with a tremendous force. They resolve so many fundamental problems at once that they seem also to promise that they will resolve all fundamental problems, clarify all obscure issues.”) (citing SusAnNe LANGer, PhiLOSOPHY IN A NeW Key (1953)). 
[Vol. 10: 2, 2010]

PEPPERDINE DISPUTE RESOLUTION LAW JOURNAL

bargaining scholars: the Prospect Theory ${ }^{33}$ of Daniel Kahneman and Amos Tversky. ${ }^{34}$ Initially, Prospect Theory ${ }^{35}$ had its largest impact on legal

33. Daniel L. Kahneman \& Amos Tversky, Prospect Theory: An Analysis of Decision under Risk, 47 ECONOMETRICA 263, 274 (1979) [hereinafter Kahneman \& Tversky, Prospect Theory] ("[This] paper presents an ... account of individual decision making under risk, called prospect theory . . . developed for simple prospects with monetary outcomes and stated probabilities .....”). I will use the term "Prospect Theory" to refer mostly to Kahneman and Tversky's work on heuristics and biases, although they divided their research into three separate and distinct programs. Daniel Kahneman, Maps of Bounded Rationality: Psychology for Behavioral Economics, 93 AM. ECON. REV. 1449, 1449 (2003) [hereinafter Kahneman, Maps] (noting that the "three separate programs of research" included an exploration of the heuristics and biases used to make judgment under uncertainty, the development of "prospect theory, a model of choice under risk," and a study of "framing effects and ... their implications for rational-agent models"). The term is used this way colloquially and it will not introduce confusion into the discussion for me to use it in that way as well. Prospect Theory also is a less cumbersome term than "heuristics and biases based system of decision making and judgment." Prospect Theory is part of a larger body of scholarship that goes variously by the names of Behavioral Decision Theory, Behavioral Economics, or Behaviorism, and I will use these terms interchangeably with Prospect Theory as well. See Gregory Mitchell, Why Law and Economics' Perfect Rationality Should Not Be Traded for Behavioral Law and Economics' Equal Incompetence, 91 GEO. L.J. 67, 78-83 (2002) [hereinafter Mitchell, Why Law and Economics] (describing the debate over names); Ward Edwards, Behavioral Decision Theory, 12 ANN. Rev. PSYCHOL. 473, 473 (1961) (coining the phrase "behavioral decision theory" to refer to "psychological and economic theories of riskless and risky decision making, the theory of games, and the experiments relating to these theories."). None of the foregoing distinctions are critical to the present non-technical discussion.

34. Professor Kahneman was awarded the 2002 Sveriges Riksbank (Bank of Sweden) Prize in Economic Sciences in Memory of Alfred Nobel (the Nobel Memorial Prize in Economics) for his contribution to the development of the Prospect Theory. See Kahneman, Maps, supra note 33, at 1449 (revised version of Professor Kahneman's Bank of Sweden Prize lecture). Professor Tversky died in 1996. See News Release, Stanford University, Amos Tversky, Leading Decision Researcher, Dies at 59, STANFORD NEWS SERVICE (June 5, 1996), available at http://newsservice.stanford.edu/pr/96/960605tversky.html. Prospect Theory does not lack skeptics and critics both in the social sciences and in law. See, e.g., Jennifer Arlen, Comment: The Future of Behavioral Economic Analysis of Law, 51 VAND. L. REV. 1765 (1998); Jonathan L. Cohen, Can Human Irrationality Be Experimentally Demonstrated?, 4 BEHAV. \& BRAIN SCI. 317 (1981); Daniel A. Farber, Toward a New Legal Realism, 68 U. CHI. L. REV. 279 (2001); Gerd Gigerenzer, How to Make Cognitive Illusions Disappear: Beyond "Heuristics and Biases," 2 EUR. REV. SOC. PSYCHOL. 83 (1991); Robert A. Hillman, The Limits of Behavioral Decision Theory in Legal Analysis: The Case of Liquidated Damages, 85 CORNELL L. REV. 717 (2000); Samuel Issacharoff, Can There Be a Behavioral Law and Economics?, 51 VAND. L. REV. 1729 (1998); Mark Kelman, Behavioral Economics as Part of a Rhetorical Duet: A Response to Jolls, Sunstein, and Thaler, 50 STAN. L. REV. 1577 (1998); Donald C. Langevoort, Behavioral Theories of Judgment and Decision Making in Legal Scholarship: A Literature Review, 51 VAND. L. REV. 1499 (1998); Mitchell, Taking Behavioralism Too Seriously?, supra note 24, at 1938-95; Mitchell, Why Law and Economics, supra note 33, at passim; Richard A. Posner, Rational Choice, Behavioral Economics, and the Law, 50 STAN. L. REV. 1551 (1998); Robert E. Scott, The Limits of Behavioral Theories of Law and Social Norms, 86 VA. L. Rev. 1603 (2000); Thomas S. Ulen, The Growing Pains of Behavioral Law and Economics, 51 VAND. L. REV. 1747 (1998). 
scholarship in the fields of private law doctrine, administrative regulation, evidence, and jury deliberation, ${ }^{36}$ but now it also is beginning to be used to

35. Prospect Theory has a charmingly entitled sibling (or perhaps offspring), known as "Happiness Theory," (now perhaps "Hedonic Adaptation Theory"), which soon may overtake it in popular appeal. See Sue M. Halpern, Are You Happy?, 55 N.Y. ReV. OF BoOKS, Apr. 3, 2008, 24, 24-27 (describing the field of Happiness Research). In 2007, for example, the University of Chicago Law School held a conference on the Legal Implications of the New Happiness Research. The papers from the conference were published in a special issue of the Journal of Legal Studies, available at http://www.journals.uchicago.edu/toc/j1s/2008/37/s2. Two of the conference participants published a Happiness Theory based book on economics, see RICHARD H. THALER \& Cass R. Sunstein, Nudge: Improving Decisions About Health, Wealth, and Happiness (2008)), which became the basis of a major shift in national economic policy. See John Cassidy, Economics: Which Way for Obama?, 55 N.Y. REV. OF BOOKS 30-34 (2008) (noting that "[i]n a number of cases, the measures that Thaler and Sunstein recommended are mirrored by proposals in Obama's voluminous policy papers, which can be downloaded from his Web site"). Legal bargaining theorists also have begun to incorporate Happiness Research into bargaining scholarship. See, e.g., John Bronsteen, Christopher Buccafusco \& Jonathan S. Masur, Hedonic Adaptation and the Settlement of Civil Lawsuits, 108 ColuM. L. REV. 1516 (2008). However, not everyone is happy with Happiness Research. Noting that its central conception of "hedonic flow" is based on Jeremy Bentham's idea of pleasure as a "single sensation," Martha Nussbaum characterizes Happiness Research (repeating Mill's criticism of Bentham), as expressing "the empiricism of one who has had little experience." Martha C. Nussbaum, Who Is the Happy Warrior? Philosophy Poses Questions to Psychology, 37 J. LEGAL STUD. S81, S82-S83 (2008), available at http://www.journals.uchicago.edu/doi/pdf/10.1086/587438. Nussbaum concludes that "the appeal to subjective well-being, as currently used in the psychological literature, is not utterly useless, but at present it is so riddled with conception confusion and normative naïveté that we had better pause and sort things out before going any further." Id. at S108.

36. Prentice, Chicago Man, supra note 24, at 1755-64 (describing the "Implications for Legal Theory" of heuristics and biases research); Jeffrey Rachlinksi, The "New" Law and Psychology: A Reply to Critics, Skeptics and Cautious Supporters, 85 CoRnELl L. Rev. 739, 766 (2000) ("The new law and psychology adds the study of litigants, manufacturers, tortfeasors, contracting parties, corporate officers, spouses, parents, fiduciaries, and property owners to the research agenda."). See also Dan Orr \& Chris Guthrie, Anchoring, Information, Expertise, and Negotiation: New Insights from Meta-Analysis, 21 OHIO ST. J. ON DisP. Resol. 597, 624 (2006). The Theory's most highly visible scholarly contribution is its challenge to the empirical foundations and decision model of Law \& Economics scholarship. See Mitchell, Taking Behavioralism Too Seriously?, supra note 24, at 1910 n.5 ("Within the last five years alone, five law reviews have conducted symposia addressing the question of how psychology and behavioral economics may inform legal decision making."). The debate between the two competing conceptions of rational choice is now largely on hold, with both sides claiming victory. Compare Mitchell, Why Law and Economics, supra note 33, at 72, 76 (legal decision theory "cannot lay claim to empirical validity superior to that of the perfect rationality assumption"), and (concluding that the "development of a general model of legal behavior that is both reasonably descriptive and parsimonious [is] unlikely"), and Matthew D. Adler \& Eric A. Posner, Happiness Research and Cost Benefit Analysis, 37 J. LEGAL STUD. S253, S255 (2008), available at http://www.journals.uchicago.edu/doi/pdf/10.1086/590188 ("The [happiness] literature does not undermine the normative basis of [cost-benefit analysis] - does not even address it - and its empirical findings do not contradict the main empirical premises of [cost-benefit analysis]."), with Prentice, Chicago Man, supra note 24, at 1774 ("[T] he debate over whether the economists' Chicago Man or the psychologists' K-T Man better describes reality is over; the psychologists won."), and Rachlinski, supra note 26, at 766 ("The new law and psychology has begun to blaze a new trail and to inspire unique questions about law that legal scholars would not 222 
[Vol. 10: 2, 2010]

PEPPERDINE DISPUTE RESOLUTION LAW JOURNAL

reconceptualize legal bargaining theory as well. ${ }^{37}$ The project is gaining momentum in the legal bargaining literature notwithstanding substantial reasons to be skeptical of it, so I shall attempt to explain some of those reasons here. ${ }^{38}$

Prospect Theory also is too large and complex of a phenomenon to examine fully in a single discussion. Therefore, after a brief description of its basic theoretical framework, I will restrict discussion to one of the theory's central concepts, that of "anchoring and adjustment" (anchoring), and the role it allegedly plays, or can be made to play, in influencing bargaining outcomes. ${ }^{39}$ Of all the Prospect Theory concepts, anchoring has

otherwise have asked."), and Russell B. Korobkin \& Thomas S. Ulen, Law and Behavioral Science: Removing the Rationality Assumption from Law and Economics, 88 CAL. L. REV. 1051, 1053 (2000) (suggesting that a law and behavioral science perspective may provide "a more nuanced understanding of human behavior"). For a middle view, see Frank B. Cross, In Praise of Irrational Plaintiffs, 86 CORNELL L. REV. 1, 32 (2000) ("The prevailing battle between law and economics and behavioral economics is ... misguided.... Behavioralism is not so much an alternative to law and economics as it is a complement. It supplements the classic model and explains why deviations may occur from the model, but it does not supplant that model."). See also infra note 44.

37. Russell Korobkin, Aspirations and Settlement, 88 CoRnell L. Rev. 1, 14 (2002) (describing studies by legal bargaining theorists that rely on Prospect Theory to construct theories of settlement) (citing Jeffrey J. Rachlinksi, Gains, Losses, and the Psychology of Litigation, 70 S. CAL. L. REV. 113, 116 (1996)); Russell Korobkin \& Chris Guthrie, Psychological Barriers to Litigation Settlement: An Experimental Approach, 93 MICH. L. Rev. 107, 109 (1994); Chris Guthrie, Framing Frivolous Litigation: A Psychological Theory, 67 U. CHI. L. REV. 163, 168-69 (2000)); Id. at 53-60 (describing prescriptive advice for bargainers based on Prospect Theory findings); Malhotra \& Bazerman, Psychological Influence, supra note 32, at 514-19 (describing the application of Prospect Theory insights to the development of bargaining technique); Dan Orr \& Chris Guthrie, supra note 36 (same).

38. Chad M. Oldfather, Heuristics, Biases, and Criminal Defendants, 91 MARQ. L. ReV. 249 (2007) ("My purpose here is ... to introduce a note of caution with respect to the application of [Behavioral Law and Economics] research to the workings of the criminal justice system ....").

39. As in any "telephone game," descriptions of the various Prospect Theory concepts vary somewhat as they are repeated from writer to writer. For example, Matthew Adler describes Prospect Theory itself as a heuristic. See Matthew D. Adler, Bounded Rationality and Legal Scholarship, in THEORETICAL FOUNDATIONS OF LAW AND ECONOMICS 137 (Mark White ed., 2009) (manuscript at 14), available at http://papers.ssrn.com/sol3/papers.cfm?abstract_id=1095874 ("one heuristic identified by Tversky and Kahneman [is] 'prospect theory"'). But Daniel Kahneman describes it as a "model of choice under risk." See Kahneman, Maps, supra note 33, at 1449. Prospect Theory might have abandoned, or at least downgraded, the concept of anchoring. See Daniel Kahneman \& Shane Frederick, Representativeness Revisited: Attribute Substitution in Intuitive Judgment, in Heuristics AND BiAses: The Psychology of INTUITIVE JudgMENT 49, 56 (Thomas Gilovich et al. eds., 2002) ("It has become evident that an affect heuristic should replace anchoring in the list of major general-purpose heuristics.") (citation omitted); Fritz Strack \& Thomas Mussweiler, Heuristic Strategies for Estimation Under Uncertainty: The Enigmatic Case of Anchoring, in FOundations OF SOCIAL COGNITION: A FESTSCHRIFT IN HONOR OF ROBERT S. 223 
the closest and most obvious connection to negotiation outcome, even to the point of providing the precise mechanism by which agreement is reached. It also is the subject of several highly regarded articles by prominent scholars in leading journals, ${ }^{40}$ and is perhaps the most thoroughly analyzed and empirically documented of all the Prospect Theory concepts, ${ }^{41}$ at least in the legal bargaining literature. Any difficulties encountered in incorporating the concept into legal bargaining theory will recur many times over in working with other parts of the Prospect Theory framework. All of this makes anchoring an excellent, perhaps even the best, surrogate for examining Prospect Theory's contributions to legal bargaining theory in general.

\section{PRosPeCt TheORY DESCRIBED}

Prospect Theory is a theory of human decision-making under conditions of risk and uncertainty. ${ }^{42}$ It is a cognitive theory, not exclusively behavioralist or mentalist, concerned with the way in which external effects on behavior are mediated by mental processes arising in the mind of the

WYER, JR. 79, 92-93 (Galen V. Bodenhausen \& Alan J. Lambert eds., 2003) ("In retrospect, anchoring has lost its status as a unique phenomenon with its own regularities. Instead, it has found its place as a special case of basic principles that served as the pillars of a psychological subdiscipline whose explanatory power has proven to be exceptionally strong."). But see Daniel T. Gilbert, Inferential Correction, in HEURISTICS AND BIASES, supra, at 167 (Anchoring and adjustment "describe[] the process by which the human mind does virtually all of its inferential work."); Manish Agrawal \& Kaushal Chari, Learning Negotiation Support Systems in Competitive Negotiations: A Study of Negotiation Behaviors and System Impacts, 5 INT'L J. INTELLIGENT INFO. TECH. 1 (forthcoming 2009) (manuscript at 8), available at http://papers.ssrn.com/sol3/papers.cfm?abstract_id=904619 ("Anchoring and framing are the most important of the [cognitive biases identified by Kahneman and Tversky].”).

40. Orr \& Guthrie, supra note 36; Chris Guthrie \& Jeffrey J. Rachlinski, Insurers, Illusions of Judgment \& Litigation, 59 VAND. L. REV. 2017, 2027-33 (2006) (describing the effects of anchoring on bargaining); Russell Korobkin \& Chris Guthrie, Heuristics and Biases at the Bargaining Table, 87 MARQ. L. REV. 795, 799-800 (2004).

41. Malhotra \& Bazerman, supra note 32, at 513 ("the application of anchoring and insufficient adjustment to negotiation research" ... "has already been made in the existing literature") (citations omitted); Guthrie \& Rachlinksi, supra note 40, at 2026-33 (describing anchoring studies); Orr \& Guthrie, Anchoring, supra note 36, at 608-11, 614-23 (same).

42. Kahneman \& Tversky, Prospect Theory, supra note 33, at 263, 274; Kahneman, Maps, supra note 33 , at 1449, 1460. Kahneman and Tversky described decisions under risk as presenting a choice between "prospects or gambles" among alternatives with different probabilities, thus the name Prospect Theory. Kahneman \& Tversky, Prospect Theory, supra note 33, at 263 ("Decision making under risk can be viewed as a choice between prospects or gambles."). Not everyone agrees on the origins of the name. See Thayer Watkins, Kahneman and Tversky's Prospect Theory, http://www.sjsu.edu/faculty/watkins/prospect.htm (last visited Nov. 14, 2009) ("Daniel Kahneman and Amos Tversky called their studies of how people manage risk and uncertainty Prospect Theory for no other reason than that it is a catchy, attention-getting name."). There is a revised version of the theory called cumulative Prospect Theory. Amos Tversky \& Daniel Kahneman, Advances in Prospect Theory: Cumulative Representation of Uncertainty, 5 J. RISK \& UNCERTAINTY 297 (1992). 224 
[Vol. 10: 2, 2010]

PEPPERDINE DISPUTE RESOLUTION LAW JOURNAL

actor. ${ }^{43}$ It also is a descriptive theory, not a normative one, ${ }^{44}$ best known for its critique (as psychologically and empirically unrealistic) ${ }^{45}$ of the expected utility model of rational choice ${ }^{46}$ and the development of an alternative

43. See Galen V. Bodenhausen \& Alan J. Lambert, Foundations of Social Cognition: An Introduction, in FOUNDATIONS OF SOCIAL COGNITION, supra note 39, at 1, 2 ("Rather than concede that the mind must forever remain a murky and theoretically irrelevant black box, social cognition researchers sought to specify the cognitive structures and processes that putatively shape our understanding of social situations and that mediate our reactions to them.").

[Prospect Theory] is a descendant of the cognitive revolution, which displaced behavioral

psychology in the 1960s as the leading school of thought in experimental psychology.

Behaviorists make no inferences about human thought processes, which makes their work

analogous to microeconomics. By contrast, human thought processes are the targets of study for cognitive psychologists. [Prospect Theory] relies upon inferences that

psychologists make about cognitive processes and is therefore a radical departure from behaviorism and from microeconomic theory.

Rachlinski, supra note 26, at 740.

44. Kahneman, Maps, supra note 33, at 1456 ("One novelty of prospect theory was that it was explicitly presented as a formal descriptive theory of the choices that people actually make, not as a normative model.”); JAMES MONTIER, BEHAVIOURAL FINANCE: INSIGHTS INTO IRRATIONAL MINDS AND MARKETS 20 (2002) ("[U]nlike expected utility theory which concerns itself with how decisions under uncertainty should be made (a prescriptive approach), $[\mathrm{P}]$ rospect $[\mathrm{T}]$ heory concerns itself with how decisions are actually made (a descriptive approach).") (emphasis omitted); Kahneman, Maps, supra note 33, at 1456 (describing how Prospect Theory was "a departure from a long history of choice models that served double duty as normative logics and as idealized descriptive models"); Mitchell, Taking Behavioralism Too Seriously?, supra note 24, at 1943 ("Behavioral decision theory ... offers a descriptive account of judgment ...."). Some bargaining theorists argue for the adoption of Prospect Theory techniques on the ground that they produce better bargaining practice. See, e.g., Malhotra \& Bazerman, supra note 32, at 525 ("[I]n many cases, negotiators do want to claim as much as possible... [in such cases] we see the honest use of the psychology of influence as an appropriate and ethical set of tools.").

45. Kahneman \& Tversky, Prospect Theory, supra note 33, at 263 ("The present paper describes several classes of choice problems in which preferences systematically violate the axioms of expected utility theory. In the light of these observations, we argue that utility theory, as it is commonly interpreted and applied, is not an adequate descriptive model . . .."); Kahneman, Maps, supra note 33, at 1449 (criticizing rational agent models as "psychologically unrealistic"). But see Oldfather, supra note 38, at 260 ("[T]he greater descriptive accuracy provided by behavioral economics might be more apparent than real."); Martha Nussbaum, supra note 35, at S86, S88, S91 (arguing that the subjective state psychologists' empirical studies of feelings are too conceptually breezy to discover accurate information about real life phenomena, using Daniel Kahneman as an example); Mitchell, Why Law and Economics, supra note 33, at 120-23 (questioning the greater realism and predictive power of Behavioral Decision Theory).

46. Kahneman, Maps, supra note 33, at 1454, 1470 (Findings [of Prospect Theory] indicate that the traditional separation between belief and preference in analyses of decision making is psychologically unrealistic.") (describing the "compound cognitive system" sketched by Prospect Theory as different "in important respects from another paragon, the rational agent assumed in economic theory"). See also Cass R. Sunstein, Behavioral Analysis of Law, 64 U. CHI. L. ReV. $1175,1175-79$ (1997) (arguing that Behavior Decision Theory will be used principally to modify 225 
conception of decision-making ${ }^{47}$ based on a set of cognitive heuristics and biases that inform and distort decision making and judgment (anchoring, framing, reactive devaluation, and the like) ${ }^{48}$ and that grow out of research on the subject of "bounded rationality." 49

rather than undermine existing theories of rational choice); Christine Jolls, Cass R. Sunstein \& Richard Thaler, A Behavioral Approach to Law and Economics, 50 StAN. L. Rev. 1471, 1547 (1998) (arguing that Behavior Decision Theory will be used principally to modify rather than undermine existing theories of rational choice); Posner, supra note 34, at 1558-61 (arguing that Behavioral Decision Theory is primarily a means of attacking law and economics rather than an affirmative foundation for a new model of choice). But see Rachlinski, supra note 26, at 750 (Behavioral Decision Theory's "emphasis on errors is not merely an effort to dislodge rationalchoice theory. Rather, BDT is an attempt to develop a novel theory of human decision making."). The application of [Behavioral Decision Theory] to law will do more than just provide another criticism of, or addendum to, law and economics. A legal scholar familiar with the research in BDT will ask different questions about law than scholars schooled in either law and economics or traditional legal analysis.

Rachlinski, supra note 26, at 764-65.

The breadth of legal decision theory's assault on the rationality assumption cannot be overstated: legal decision theorists collectively contend that all judgments and decisions of legal importance-whether made by ordinary citizens or criminals, litigants or lawyers, judges or jurors-involve imperfect psychological processes that consistently cause irrational judgments and choices to be made.

Mitchell, Taking Behavioralism Too Seriously?, supra note 24, at 1918. Prentice, Chicago Man, supra note 24, at 1765-73 (describing the relationship between Behavioral Decision Theory and Law $\&$ Economics).

47. In his Bank of Sweden Prize lecture Kahneman described his work with Tversky as compris[ing] three separate programs of research .... The first explored the heuristics that people use and the biases to which they are prone in various tasks of judgment under uncertainty, including predictions and evaluations of evidence. The second was concerned with [P]rospect [T]heory, a model of choice under risk and with loss aversion in riskless choice. The third ... dealt with framing effects and with their implications for rational-agent models.

Kahneman, Maps, supra note 33, at 1449 (citations omitted).

48. See Amos Tversky \& Daniel Kahneman, Judgment Under Uncertainty: Heuristics and Biases, 185 SCIENCE 1124, 1131 (1974) ("These heuristics are highly economical and usually effective, but they lead to systematic and predictable errors.") (describing the relationship of heuristics to biases), and at 1131 ("These heuristics are highly economical and usually effective, but they lead to systematic and predictable errors."); Kahneman, Maps, supra note 33, at 1450 ("intuitive thinking can also be powerful and accurate"); Guthrie \& Rachlinski, supra note 40 , at 2024 ("Often, heuristics are adaptive, leading to good decision outcomes; other times, however, they can lead people astray.") (citation omitted); Korobkin \& Guthrie, supra note 40, at 796 n.5 ("While scholars in the Tversky-Kahneman tradition tend to emphasize how heuristics can lead decision makers astray ... scholars in the Gigerenzer tradition tend to emphasize how helpful heuristics can be.") (citation omitted); Christine Jolls \& Cass R. Sunstein, Debiasing Through Law, 35 J. LEGAL STUD. 199, 203-06 (2006) (describing "judgment errors" and "departures from expected utility theory" produced by bounded rationality); J.D. Trout, Paternalism and Cognitive Bias, 24 LAW \& PHIL. 393, 396-408 (2005) (overview of cognitive biases); R.E. Nisbett \& E. Borgida, Attribution and the Psychology of Prediction, 32 J. PERSONALITY \& SOC. PSYCHOL. 932, 935 (1975) (describing how the results of heuristics and biases research have "bleak implications" for human rationality); Max H. Bazerman \& Margaret A. Neale, Heuristics in Negotiation: Limitations to Effective Dispute 226 
[Vol. 10: 2, 2010]

PEPPERDINE DISPUTE RESOLUTION LAW JOURNAL

The components of the theory were described first by the psychologists ${ }^{50}$ Daniel Kahneman and Amos Tversky in a now famous 1979 article in the journal Econometrica. ${ }^{51}$ Intrigued by the fact that people both purchase insurance and play lotteries, a combination that would seem strange for a consistent rational agent, ${ }^{52}$ Kahneman and Tversky, in a series of thought experiments based on the Allais paradox, ${ }^{53}$ set out to examine

Resolution, in Judgment AND DECISION MAKING: AN INTERDISCIPLINARY READER 311, 317 (Hal R. Arkes \& Kenneth R. Hammond eds., 1986) ("[I]ndividuals are generally affected by systematic deviations from rationality."). Professor Weinstein provides helpful illustrations of how cognitive biases can be used in legal practice both to manipulate and inform decisions. See Weinstein, supra note 31 , at $826-27$.

49. See Herbert A. Simon, A Behavioral Model of Rational Choice, 69 Q.J. ECON. 99, 114 (1955) (describing "a choosing organism of limited knowledge and ability" as a substitute for economic man); Herbert A. Simon, Rationality as Process and as Product of Thought, AM. ECON. REV., May 1978, at 1, 10 (describing "a choosing organism of limited knowledge and ability" as a substitute for economic man); Herbert A. Simon, Information Processing Models of Cognition, 30 ANN. REV. PSYCHOL. 363 (1979) (describing "a choosing organism of limited knowledge and ability" as a substitute for economic man). See also Kahneman, Maps, supra note 33, at 1449 ("Herbert A. Simon had proposed much earlier that decision makers should be viewed as boundedly rational, and had offered a model in which utility maximization was replaced by satisficing."); Gerd Gigerenzer \& Peter M. Todd, Fast and Frugal Heuristics, in Simple Heuristics That MaKe Us SMART 3, 12-14 (Gerd Gigerenzer et al. eds., 1999) [hereinafter SiMPLE HeuRISTICS] (describing Simon's role in developing the concept of bounded rationality). The heuristics and biases conception of decision making and judgment differs from the conception of "bounded rationality" principally in the nature of the processes involved. Steven A. Sloman, Rational Versus Arational Models of Thought, in THE NATURE OF COGNITION 557, 575 (Robert J. Sternberg ed., 1999). "Bounded rationality assumes that people are using a rational inference procedure; they are just limited in their ability to fully exploit it. The [heuristics and biases] approach assumes that people are using an arational procedure that approximates rational inference." Id.

50. While they won the Bank of Sweden Prize for Economic Sciences, see supra note 34, Kahneman and Tversky "viewed [their] research primarily as a contribution to psychology, with a possible contribution to economics as a secondary benefit. [They] were drawn into the interdisciplinary conversation by economists who hoped that psychology could be a useful source of assumptions for economic theorizing ...." Kahneman, Maps, supra note 33, at 1449.

51. Kahneman \& Tversky, Prospect Theory, supra note 33, at 263.

52. Id. at 269, 281, 286 ("In prospect theory, the overweighting of small probabilities favors both gambling and insurance, while the S-shaped value function tends to inhibit both behaviors.") (discussing the question of "why ... people [would] spend so much money to purchase insurance policies at a price that exceeds the expected actuarial cost, and reporting evidence that "people prefer what is in effect a lottery ticket over the expected value of that ticket").

53. Id. at 265 ("[T] The Allais paradox is a choice problem created by Maurice Allais, a French economist and winner of the 1988 Nobel Memorial Prize in Economics, to show that assumptions made by expected utility theory contradict the nature of real life decision making. See SCOTT Plous, The PSYCHOLOGY OF JudGMENT AND DECISION MAKING 84-87 (1993) (describing the Allais paradox). But see Maurice Allais, Abstract, Allais Paradox, in The New PALgRAVE Dictionary OF ECONOMICS (Steven N. 227 
empirically how people make decisions about risk. They discovered that most people employ "two modes of thinking and deciding, which correspond roughly to intuition and reasoning." 54 Reasoning is deliberate, rulegoverned, self-monitoring, verbally explicit, and effortful, whereas intuiting is spontaneous, associative, automatic, impressionistic, and effortless. ${ }^{55}$ Most day-to-day judging is intuitive, occupying a position someplace between the automatic operation of perception (i.e., seeing, hearing, touching), and the deliberate operation of reasoning, ${ }^{56}$ and like perception, it is "reference dependent." 57 People determine their preferences by weighing

Durlauf \& Lawrence E. Blume eds., 2d ed. 2008), available at http://www.dictionaryofeconomics.com/article?id=pde2008_A000074 (“" $[\mathrm{T}]$ here is no paradox once we accept the non-identity of monetary and psychological values and the importance of the distribution of cardinal utility about its average value.").

54. Kahneman, Maps, supra note 33, at 1450 (describing System 1 (intuition) and System 2 (reasoning)). The System 1/System 2 framework represents a development over the two-stage "editing/evaluation" framework described in the original Prospect Theory article. See Kahneman \& Tversky, Prospect Theory, supra note 33, at 274 ("Prospect Theory distinguishes two phases of the choice process: an early phase of editing and a subsequent phase of evaluation.").

Simply put, we lack the cognitive capacity to undertake the analyses necessary to be fully rational with respect to all of our choices and actions. As a consequence, we tend to rely on certain mental shortcuts-heuristics - that generate behavior that, while often at least roughly in accord with the prescriptions of rationality, will systematically depart from it in significant ways. And we are susceptible to certain distortions in our thoughtbiases - that render us unable to rationally assess the information with which we are presented. (citations omitted).

See also Oldfather, supra note 38, at 251.

55. Kahneman, Maps, supra note 33, at 1451. Kahneman explains that "[t]he difference in effort provides the most useful indications of whether a given mental process should be assigned to [intuition or reason]." Id.

56. Kahneman argues that the close relationship between perceiving and intuiting permits the "vast store of scientific knowledge available about perceptual phenomena [to] be a source of useful hypotheses about the workings of intuition." Id. at 1452. See also Kahneman \& Tversky, Prospect Theory, supra note 33, at 277 (describing how the principles that govern the perceptual apparatus apply to perceptions of "non-sensory attributes such as health, prestige, and wealth."). Professor Mitchell makes a similar distinction between "first and second order thoughts." See Gregory Mitchell, Second Thoughts 8, (Aug. 27, 2009) (unpublished manuscript), available at http://papers.ssrn.com/abstract=1290243 [hereinafter Mitchell, Second Thoughts].

57.

An essential feature of the present theory is that the carriers of value are changes in wealth or welfare, rather than final states. ... [V]alue should be treated as a function in two arguments: the asset position that serves as reference point, and the magnitude of the change ... from that reference point.

Kahneman \& Tversky, Prospect Theory, supra note 33, at 277. Kahneman, Maps, supra note 33, at 1456 (in Prospect Theory "the carriers of utility are gains and losses" from a reference point). See also Reid Hastie \& Robyn M. DAWES, RATIONAL ChOICE IN AN UnCERTAin World: The PSYCHOLOGY OF JUDGMENT AND DECISION MAKING 216 (2001) ("The addition of a moveable reference level is the major difference between [P] rospect [T] heory and traditional economic utility theories."). Kahneman argued that "it is quite surprising that in standard economic analyses the 228 
[Vol. 10: 2, 2010]

PEPPERDINE DISPUTE RESOLUTION LAW JOURNAL

attitudes toward gains and losses in relation to a reference point, and measure their overall utility in terms of changes in wealth rather than states of wealth. ${ }^{58}$ The reason for this, Kahneman explained, is that perceptions of

[u]tility cannot be divorced from emotion, and emotions are triggered by changes. A theory of choice that completely ignores feelings such as the pain of losses and the regret of mistakes is not only descriptively unrealistic, it also leads to prescriptions that do not maximize the utility of outcomes as they are actually experienced ....

Kahneman and Tversky found that in making intuitive judgments people attach more weight to certainty than probability, value gain more than loss (which produces risk-averse behavior toward loss and risk-seeking behavior toward gain), ${ }^{60}$ and compare alternatives in terms of decision weights ${ }^{61}$

utility of decision outcomes is assumed to be determined entirely by the final state of endowment, and is therefore reference-independent." Kahneman, Maps, supra note 33, at 1455. He named this assumption "Bernoulli's error" after the eighteenth-century Dutch mathematician who first defined the expected utility hypothesis in terms of maximizing states of wealth. Id. (citing Daniel Bernoulli, Exposition of a New Theory on the Measurement of Risk, 22 ECONOMETRICA 23 (1954).

58. Kahneman and Tversky credit Harry Markowitz with being the "first to propose that utility be defined on gains and losses rather than on final asset positions." Kahneman \& Tversky, Prospect Theory, supra note 33, at 276 (citing Harry Markowitz, The Utility of Wealth, 60 J. POL. ECON. 151 (1952)).

[Prospect Theory] is based on the idea that people evaluate gains and losses ... from some neutral or status quo point, an assumption [that is] consistent with the adaptationlevel findings that occur not just in perception but in virtually all experience. That is, we adapt to a constant level of virtually any psychological dimension and find it to be neutral. In a similar way, we adapt to the reduced light in a movie theater when we enter it - finding it not particularly dark after a few seconds - and then readapt to the much brighter light outside when we leave the theater-finding it not to be unusually bright after a few seconds.

See also Robyn M. DAwes, EVERyday IRRATIONALITY: How PSEUdo-SCIENTISTS, LunATICS, AND THE REST OF US SYSTEMATICALLY FAIL TO THINK RATIONALLY 195 (2001).

59. Kahneman, Maps, supra note 33, at 1457.

60. Kahneman \& Tversky, Prospect Theory, supra note 33, at 279 ("A salient characteristic of attitudes to changes in welfare is that losses loom larger than gains.").

61. Id. at 280-84 (describing "the Weighting Function"). A decision weight is the marginal contribution of value over the status quo, judged from a decision maker's frame of reference, assigned to a particular outcome. Prospect theory also differs from expected utility theory in the way it handles the probabilities attached to particular outcomes. Classical utility theory assumes that decision makers value a 50 percent chance of winning as exactly that: a 50 percent chance of winning. In contrast, prospect theory treats preferences as a function of "decision weights," and it assumes that these weights do not always correspond to probabilities. Plous, supra note 53, at 98. See also Ward Edwards, Subjective Probabilities Inferred from Decisions, 69 Psychol. REv. 109 (1962) (first proposing the replacement of probabilities with more general weights). 
rather than outcome probabilities. ${ }^{62}$ They also base judgments on accessible data rather than all relevant information, ${ }^{63}$ suppress ambiguity and uncertainty associated with choice ${ }^{64}$ favor transient emotions over long-term beliefs, ${ }^{65}$ construct analytical categories in terms of prototypes ${ }^{66}$ rather than extensional variables, ${ }^{67}$ make choices on the basis of feelings rather than

62. Kahneman \& Tversky, Prospect Theory, supra note 33, at 277, 280 (“[D]ecision weights do not coincide with stated probabilities.") ("Decision weights measure the impact of events on the desirability of prospects, and not merely the perceived likelihood of these events.").

63. Kahneman, Maps, supra note 33, at 1452 ("A defining property of intuitive thoughts is that they come to mind spontaneously, like percepts. The technical term for the ease with which mental contents come to mind is accessibility."). While "[t]he impressions that become accessible in any particular situation are mainly determined ... by the actual [physical] properties of the object of judgment... [a]nalogous effects ... occur with more abstract stimuli... [and] make different thoughts accessible." Id. at 1453-54. Reliance on accessible information is popularly known as the "availability heuristic." Tversky \& Kahneman, supra note 48, at 1127-28. It also has been called the "salience" or "vividness" heuristic. See, e.g., Richard Nisbett \& LeE Ross, Human INFERENCE: STRATEGIES AND SHORTCOMINGS OF SOCIAL JUDGMENT 8 (1980) (“[P]eople effectively assign inferential weight to physical and social data in proportion to the data's salience and vividness.").

64. Kahneman \& Tversky, Prospect Theory, supra note 33, at 271, 275 ("In order to simplify the choice between alternatives, people often disregard components that the alternatives share, and focus on components that distinguish them. This approach to choice problems may produce inconsistent preferences ....") (citation omitted) (describing how people simplify prospects "by rounding probabilities or outcomes."); Kahneman, Maps, supra note 33, at 1454 ("Doubt is a phenomenon of [reasoning], an awareness of one's ability to think incompatible thoughts about the same thing ... [But] experienced decision makers working under pressure ... rarely need to choose between options because, in most cases, only a single option comes to mind.").

65. Kahneman, Maps, supra note 33, at 1457 ("The cultural norm of reasonable decisionmaking favors the long-term view over a concern with transient emotions .... On the other hand, an exclusive concern with the long term may be prescriptively sterile, because the long term is not where life is lived.").

66. Kahneman, Maps, supra note 33, at 1463 ("The prototype of a set is characterized by the average values of the salient properties of its members."). The representation of objects by their prototypes in making decisions, the use of co-called prototype heuristics, is a "remarkably consistent pattern of [cognitive] bias[]." Id. Yet it also "serves an important adaptive function. It allows new stimuli to be categorized efficiently, by comparing their features to those of category prototypes." Id.

67. Id. at 1458. Extensional variables are changes in an item that do not alter its basic character or value. Kahneman gives the following example. Imagine a disease is about to break out and it will kill six hundred people. Two programs have been proposed to combat it. Program A will save two hundred people for certain. Program B will provide a one-third probability that six hundred people will be saved and a two-thirds probability that six hundred people will die. Program $\mathrm{B}$ is an extensional variation of program A. Id. See also id. at 1467 ([I]n evaluating the utility of an experience that extends over time there is a "profound incompatibility between the ... logic of belief and choice [which] requires accurate evaluation of extensional variables ... [and] intuitive thinking [which] operates with exemplars or prototypes that have the dimensionality of individual instances and lack the dimension of extension.”). See also Kenneth J. Arrow, Risk Perception in Psychology and Econometrics, 20 ECON. INQUIRY 1 (1982) (describing the "inconsequential variation in outcome" as the property of "extensionality"). 
[Vol. 10: 2, 2010]

PEPPERDINE DISPUTE RESOLUTION LAW JOURNAL

rules ${ }^{68}$ transform difficult questions into easier ones as an aid to answering, ${ }^{69}$ and do all of these things even when the stakes are high. ${ }^{70}$ Though intuiting resembles perception more than reasoning, ${ }^{71}$ it works in tandem with reasoning to form what Kahneman and Tversky called a "compound cognitive system," deficiencies ${ }^{73}$ and provides a two-part mechanism for adjusting to change, both "a short-term process that is flexible and effortful, and a long-term process of skill acquisition that eventually produces highly effective responses at low cost." ${ }^{, 74}$ For most people, intuiting is the cognitive process underlying judgment most of the time, particularly for decisions made within a limited time frame, under deadline pressure, and without access to all of the necessary information.

It is understandable that legal bargaining scholars would be attracted to Prospect Theory. Even the simplest negotiation requires rapid-fire judgments based on incomplete data and partial understandings, made under circumstances that preclude extensive investigation and sophisticated analysis. $^{75}$ Bargainers must determine how to counter arguments they did

68. Kahneman, Maps, supra note 33, at 1466-68.

69. Tversky \& Kahneman, supra note 48, at 1124 (“[P]eople rely on a limited number of heuristic principles which reduce the complex tasks of assessing probabilities and predicting values to simpler judgmental operations."). This is achieved by a process of attribute substitution. Kahneman \& Frederick, supra note 39, at 53. "[A]n individual assesses a specified target attribute of a judgment object by substituting another property of that object- the heuristic attribute - which comes more readily to mind." Id. Kahneman and Tversky give the example of resolving a question of probability by asking whether a relevant incident comes easily to mind rather than investigating statistical evidence. Amos Tversky \& Daniel Kahneman, Availability: A Heuristic for Judging Frequency and Probability, 5 COGNITIVE PSYCHOL. 207 (1973).

70. Kahneman, Maps, supra note 33, at 1468 ("[T]he claim that high stakes eliminate departures from rationality is not supported by a careful review of the experimental evidence.") (citation omitted).

71. Tversky \& Kahneman, supra note 48, at 1124 ("The subjective assessment of probability resembles the subjective assessment of physical quantities such as distance or size.”).

72. Kahneman, Maps, supra note 33, at 1454.

73. Id. at 1451 ("System 2 monitors the activities of System 1.").

74. Id. at 1454 .

75. Korobkin \& Guthrie, supra note 40, at 798 (Negotiators need to rely on heuristics to make " fast and frugal" judgments because they "cannot know the objective values and probabilities of every option they might consider before reaching a negotiated outcome.") (quoting Jean Czerlisnki et al., How Good Are Simple Heuristics?, in Simple Heuristics, supra note 49, at 97); Jeffrey J. Rachlinski, Gains, Losses, and the Psychology of Litigation, in WIGGINS \& LOWRY, supra note 29, at 290, 296 (arguing that an understanding of Prospect Theory will provide a bargainer with leverage over an adversary).

231 
not anticipate, respond to offers whose implications are not clear, evaluate factual claims on the basis of incomplete evidence, make proposals without knowing how they will be received, and probe for information others do not want to reveal, all automatically as the opportunities present themselves in the bargaining conversation, without losing their place or direction in an overall strategic plan. Each of these tasks calls for judgments - about the situation, the case, other bargainers, the parties, extra-bargaining alternatives, and the like - that must be made instantly or not at all. Prospect Theory describes the cognitive processes through which these kinds of judgments are most naturally made. In a sense, Prospect Theory is a template for ordinary bargaining judgment and thus a natural subject of study for those who would investigate bargaining performance. How much guidance one should take from the theory is the question to which we now turn.

\section{PROSPECT THEORY’s ReLATIONSHIP TO LEGAL BARGAINING}

Prospect Theory generally ${ }^{76}$ has been criticized on a wide variety of grounds, both from within the field of psychology and without, but my focus will be narrower. I am interested only in the question of what the theory contributes to an understanding of legal bargaining practice. Thus, I will limit my discussion to uses made of the theory by legal bargaining scholars to support prescriptive claims about bargaining effectiveness. Questions about the theory's implications for restructuring substantive rules of law, legal institutions, rules of evidence and procedure, and the like, even those that define and regulate the institutions and conditions of legal bargaining, are for another day. In the sections that follow, I will describe how the methods and concepts of Prospect Theory research do not map perfectly onto the practice of legal bargaining. While many bargaining decisions are made intuitively, in the fashion described by Prospect Theory, structural features of the bargaining process often force bargainers to move beyond intuiting into reasoning if they are to perform effectively. This, in turn, makes legal bargaining a hybrid process, made up of both types of cognitive functioning identified by Kahneman and Tversky, and thus not completely amenable to Prospect Theory-based analysis. ${ }^{77}$ But first I will take up some of the objections that might be made to Prospect Theory research in general.

\footnotetext{
76. I will treat Prospect Theory and Behavioral Decision Theory as interchangeable terms for purposes of this section of the discussion. Criticisms of the latter usually will apply to Prospect Theory with equal force.

77. Criticisms discussed in this section are variations of the so-called ecological validity criticism. See Mitchell, Taking Behavioralism Too Seriously?, supra note 24, at 1985-92 (criticizing 232
} 
[Vol. 10: 2, 2010]

PEPPERDINE DISPUTE RESOLUTION LAW JOURNAL

\section{A. Prospect Theory Research Is About Decision Making More Than Bargaining}

For the most part, Prospect Theory research is based on responses to hypothetical ${ }^{78}$ decision scenarios asking questions about valuation and prediction that do not reproduce the experience of real life bargaining fully. ${ }^{79}$ While the scenarios often are described as bargaining problems, ${ }^{80}$ rarely, if ever, are subjects ${ }^{81}$ given the opportunity to interact personally to compare

Behavioral Decision Theory experiments for not presenting problems in "ecologically valid" formats);

After psychologists perform laboratory studies and derive results, they are often then able to produce hypotheses testable in the real world. Questions of ecological validity are on the minds of every psychologist who structures an experiment, and studies that lack it are often attacked. Therefore, psychologists have tested their hypotheses over and over both in the laboratory and in the field.

Prentice, Chicago Man, supra note 24, at 1697-98 (citations omitted). Ecological validity is not an across the board problem for all types of behavioral decision theory experimentation. Some legal processes - jury decision making is a good example - are more easily simulated in a laboratory than others, see Prentice, Chicago Man, supra note 24, at 1698 ("[M]ock jury research has improved so that there is little or no difference between the results of studies of mock jurors in university laboratories and the results of studies of real jurors in actual courtrooms."), though more recent jury research has recognized the importance of real life context to the validity of such experiments. See, e.g., Max Minzner, Detecting Lies Using Demeanor, Bias, and Context, 29 CARDOZO L. REV. 2557, 2567 (2008) (describing "[m]ore recent studies" finding that an observer's ability to detect lying improves when he has access to the real life context surrounding a witness's testimony). See also Gretchen B. Chapman \& Brian H. Bornstein, The More You Ask for, the More You Get: Anchoring in Personal Injury Verdicts, 10 ApPLIEd Cognitive Psychol. 519, 536 (1996) ("It is difficult to know the extent to which the results of [jury] simulations can be applied to court-room situations.") (citation omitted).

78. Subjects sometimes behave differently in situations with hypothetical consequences than in situations in which the consequences are real. See Mitchell, Why Law and Economics, supra note 33, at 114-19 (summarizing the literature on "incentive effects" in behavioral decision research).

79. Cf. Mitchell, Why Law and Economics, supra note 33, at 109 ("[B]ehavioral patterns that appear irrational from an asocial, narrow perspective focused on procedural rationality may appear quite rational from a contextualized, instrumental perspective."); Korobkin, supra note 37, at 20-21 (describing the types of experiments designed to test aspiration levels and concluding that "[i]t is not obvious ... that these findings would translate to the context of bargaining generally or settlement behavior specifically").

80. See Guthrie \& Rachlinksi, supra note 40, at 2029 (description of the "Case Settlement Evaluation" scenario).

81. Psychologists prefer a more personal term, such as participant, respondent, or individual, to the term "subject," perhaps to avoid the submissive connotation attached to the latter. See American Psychological Ass'N, Publication Manual of the AMERICAN Psychological ASSOCIATION 65 (5th ed. 2001) ("Replace the impersonal term subjects with a more descriptive term when possible and appropriate - participants, individuals, college students, children, or respondents, for example."). Following Mitchell, I will use the term subject since it is likely to be more familiar 233 
and discuss alternative resolutions to the problems, ${ }^{82}$ identify and clarify points of disagreement, argue for preferences, adjust expectations based on one another's objections, ${ }^{83}$ break off discussion to evaluate alternative options, change features of the problem to increase leverage ${ }^{84}$ seek out other partners with whom to deal, ${ }^{85}$ or try in any other way try to change situational incentives or constraints defined by the problems so as to increase one's chances of success. ${ }^{86}$ To the extent that the subjects in these experiments bargain at all, they do so privately, imaginatively, and unilaterally (all of which is to say, superficially and self-servingly), in their

to a legal audience. See Mitchell, Taking Behavioralism Too Seriously?, supra note 24, at 1945 n.69.

82. For a representative example of such a problem, in which subjects were required to assume what ordinarily would be argued about, see Linda Babcock et al., Forming Beliefs About Adjudicated Outcomes: Perceptions of Risk and Reservation Values, 15 INT'L REV. L. \& ECON. 289, 292 (1995) (subjects asked to predict what a jury would award, the minimum amount a client should accept, and the maximum amount a client should pay, in a products liability lawsuit in which the definition of comparable awards in the jurisdiction was fixed by the researchers and not subject to discussion). This is understandable since Prospect Theory experiments are designed to study decision making, not bargaining. Some legal scholars have conducted experiments of their own using quasi-bargaining problems, but these problems also lack most of the properties of real-life bargaining described in the text. See, e.g., Orr \& Guthrie, supra note 36, at 609-11.

83. See Mitchell, Taking Behavioralism Too Seriously?, supra note 24, at 1977 ("One of the clearest ways in which many behavioral decision experiments differ from many decision settings in the real world is in the lack of feedback or learning opportunities provided to subjects ... [which] increases the likelihood that irrational responses will be found ...."). See also William P. Bottom \& Paul W. Paese, Judgment Accuracy and the Asymmetric Cost of Errors in Distributive Bargaining, 8 GROUP DECISION \& NEGOT. 349, 356-57 (1999) (discussing studies showing how "[s]ubjects alter[] their expectations a great deal from the beginning of the negotiation to the end").

84. Perhaps the best example of how social science research on bargaining fixes the conditions under which subjects must operate is the "Rubinstein bargaining game," a two-person game designed to test mathematical models of settlement under the assumption of perfect information and the requirement of alternating offers. See Douglas G. Baird et Al., Game Theory and the Law 221-28 (1994) (citing Ariel Rubinstein, Perfect Equilibrium in a Bargaining Model, 50 ECONOMETRICA 97 (1982)).

85. Put in more familiar terms, subjects are not permitted to manipulate their BATNA, in Fisher and Ury's now-famous terminology. ROGER FISHER, WILlIAM URY \& BRUCE PATTON, GetTing to Yes: Negotiating Agreement Without Giving IN 97-106 (2d ed. 1991) (defining BATNA, or best alternative to a negotiated agreement).

86. Some studies attempt to overcome this difficulty by including a faux opponent in the experiment. The opponent's behavior is controlled by the researcher's instructions, however, not the opponent's own autonomous choices. Whether the opponent is cooperative or competitive, aggressive or friendly, communicative or silent, is based on what the researcher dictates and not on the opponent's own decisions based on data available in the situation. Such experiments are marginally more sophisticated than the "narrative scenario" ones described above, but their highly controlled and rigid nature deprives them of the verisimilitude needed to make the experience realistic. 
[Vol. 10: 2, 2010]

heads, effectively insulated from any adversary response, as if they are in a thought experiment rather than a negotiation. ${ }^{87}$

Some Prospect Theory research examines bargaining directly, but usually on the basis of reductionist and unrealistic models of the bargaining process. These experiments disaggregate bargaining to study its components in isolation, rather than as packages of complementary processes working together as intertwined units. ${ }^{88}$ Typically, subjects are given uncontestable and incomplete information about key factors in their problems (e.g., that the adverse bargainer is an aggressive, hard-line maximizer), ${ }^{89}$ rather than permitted to form their own conclusions about such factors based on data from the situation, or shape the situations so that the factors play a less (or more) important role than the researchers intended. Information about

87. Realistic scenarios may be more important to the study of bargaining than to the study of decision making in general. Much of what a bargainer knows and takes into account in deciding how to proceed-factual information about the case, alternatives to settlement, practical considerations in choosing one option over another, the strength of the parties' underlying legal claims, the intensity of an adversary's resistance, the sincerity of his commitment, and the likedepends, at least in part and often exclusively, on information introduced by the adversary. Bargainers will not understand the scope, sophistication, or intensity of the other side's views if they have to invent and defend those views for themselves, and they will not bargain in a representative manner if they do not understand the other side's views. This is not a problem in real life bargaining, of course, since adversaries force their views on one another without being asked.

88. But see Prentice, supra note 24, at 1696-97 (While psychology experiments are "inherently artificial in the sense that causal variables are isolated from their normal contextual variation," they still have the qualities that permit generalizing to the "complex real world.") (quoting Marilynn B. Brewer, Research Design and Issues of Validity, in HANDBOOK OF RESEARCH METHODS IN SOCIAL And Personality Psychology 14-15 (Harry T. Reis \& Charles M. Judd eds., 2000)). The attractiveness of studying bargaining piecemeal is easy to understand. If variables are defined narrowly enough, social science research can be extended almost indefinitely, making incremental additions to the theory in the manner of Vasily Alexeyev adding to the world weight-lifting records. Alexeyev, probably the greatest heavyweight lifter of all time, was rewarded by the former Soviet Union for each world record he set. Therefore, rather than lift as much as he could in any one competition, he lifted only a few pounds more than his previous record, breaking the record but also leaving himself room to break it again the next time he competed. The Soviet government did not seem to mind. Each new record warranted a new press release trumpeting the superiority of the Soviet system. See L. Cavanaugh, Red Sport Supremacy May Fall with the Wall, CouRIER-MAIL (Austl.), Nov. 13, 1989 ("Alexeyev . . . was paid 1000 roubles each time he broke a world record. He broke more than 80 world records in his career."); Skip Myslenski \& Linday Kay, Sports, CHI. TRIB., July 10, 1986, at 2 ("[Alexeyev] used to raise his own records by only a pound or two and would readily admit he did it that way because he received a bonus each time he set another mark.").

89. See Alex Stein, A Liberal Challenge to Behavioral Economics: The Case of Probability, 2 N.Y.U. J.L. \& LIBERTY 531, 535 (2007) (subjects were not told whether the court considered percentage of blue cabs in city when reporting witness's reliability at identifying blue cabs); Guthrie \& Rachlinski, supra note 40, at 2029 (subjects were told that the accident was caused solely by the negligent driving of one of the parties). 
bargainer interests and values also is often kept static rather than adjusted to take account of changing circumstances and beliefs. Little or no opportunity is given to change an adversary's state of mind $^{90}$ about what efficiency, common sense, or fairness requires, or to make out-of-the-ordinary proposals that could lead to non-standard outcomes. ${ }^{91}$ In other words, many of the dimensions of bargaining most susceptible to the influence of skill, ${ }^{92}$ are excluded from Prospect Theory research. By denying subjects the opportunity to exercise it, in fact, Prospect Theory research seems to assume that skill has little or no role to play in the bargaining process. ${ }^{93}$

Face-to-face conversation with an adversary, which forces one to evaluate options from more than a self-interested point of view, is unavoidable in real-life dispute bargaining. ${ }^{94}$ By challenging demands and the assumptions on which they are based, an adversary reminds one that not all interests are the same, not all arguments are compelling, and not all value systems are identical. To reach agreement in such circumstances, bargainers must look beyond self-interested first impressions to find principled

90. It is reasonable for a bargainer to expect that he will be able to change an adversary's state of mind. See Bottom \& Paese, supra note 83, at 356-57 (discussing studies showing that confident and optimistic bargainers are able to alter adversary expectations in negotiation).

91.

A defendant faced with a plea deal is likely to consult with family, friends, and fellow inmates before making his decision. In contrast to the sorts of well-defined, individual decisions made under fixed time constraints on which the behavioral economics literature is largely based, plea bargains present complex decisions typically made over a relatively lengthy time span after consultation with a potentially large group of people. Each one of these distinctions presents a possible roadblock to the easy application of heuristics and biases research to plea bargaining. (footnote omitted).

See Oldfather, supra note 38, at 259-60

92. See Robert J. Condlin, Bargaining with a Hugger: The Weaknesses and Limitations of a Communitarian Conception of Legal Dispute Bargaining, or Why We Can't All Just Get Along, 9 CARDOZO J. CONFLICT ResOl. 1, 16-69 (2007) (describing lawyers modifying adverse bargainer beliefs and other seemingly fixed features of negotiation through skill maneuvers).

93. Assumptions of this sort make Prospect Theory's analysis circular, building its pre(mis)conceptions tacitly into its premises and then scrupulously proving the same. This is a strange quality in a research program touted for its greater descriptive accuracy.

94. Kahneman, Maps, supra note 33, at 1468. People reason when the need to reason is called to their attention, ([T]the activation of [reasoning] depends on the factors of attention and accessibility."), and an adversary does that. Id. In a sense, an adversary is a structural instantiation of the de-biasing strategy of "consider the opposite." See supra note 200 and accompanying text. Adversarial testing may also make legal bargaining more like a joint (rather than separate) evaluation of options, and joint evaluation eliminates certain errors of intuition. See John A. List, Preference Reversals of a Different Kind: The "More Is Less" Phenomenon, 92 AM. ECON. ReV. 1636 (2002) (violations of monotonicity eliminated when traders are able to evaluate and bid on different items at the same time rather than separately) (cited in Kahneman, Maps, supra note 33, at 1465); Mitchell, Why Law and Economics, supra note 33, at 165 ("Decisions made in the absence of feedback and opportunities for learning often differ from decisions made in settings that allow for feedback and learning.").

236 
[Vol. 10: 2, 2010]

PEPPERDINE DISPUTE RESOLUTION LAW JOURNAL

positions acceptable to all sides, or middle ground positions which accommodate all interests fairly. There is no check of this sort built into Prospect Theory experimentation; no process, actor, or structural feature that performs the testing function of an adversary confrontation. ${ }^{95}$ Consequently, Prospect Theory subjects are free to adopt attitudes and make moves based on superficial, selfish, and incompletely thought-out positions that would not survive adversary challenges in real-life bargaining. Prospect Theory research may or may not reproduce the conditions of decision-making generally - that is for others to say-but it does not capture the inescapable adversarial nature of legal dispute bargaining that prevents heuristics and biases from operating unchecked. ${ }^{96}$

The absence of genuine adversarial testing also permits subjects in Prospect Theory based research on legal bargaining to give romanticized and highly self-serving (even if sincere), descriptions of how they bargain. ${ }^{97}$ Subjects will have a sense of the "correct" response ${ }^{98}$ to any given question, taken largely from consensus beliefs about how rational people act under the

95. See, e.g., Korobkin, supra note 37, at 20 ("Most of the copious amounts of empirical evidence on the effects of goals on performance ... a are collected in noncompetitive settings.").

96. Professor Lubet describes how the adversary system builds various "correctives" into lawyer interactions that reduce, even if they do not eliminate, the impact of cognitive errors. See Steven Lubet, How Lawyers (Ought To) Think (July 25, 2007) (manuscript at 5-6), available at http://papers.ssrn.com/sol3/papers.cfm?abstract_id $=1002998$.

Even when a lawyer plays fast and loose, with either facts or inferences, opposing counsel is there to point out the missing evidence or logical flaws. For every attorney who tries to take advantage of cognition errors, another is ready to rectify false impressions and caution against mistaken conclusions. Because every argument is subject to rebuttal, the adversary system itself minimizes opportunities to exploit fallacies and heuristics.

Id.

97. See, e.g., Williams, supra note 18, at 137-39; Kupfer Schneider, supra note 28, at 14748. People often overestimate their ability to perform effectively, particularly when using ambiguous and self-generated criteria of effectiveness. See David Dunning, Judith A. Meyerowitz \& Amy D. Holzberg, Ambiguity and Self-Evaluation: The Role of Idiosyncratic Trait Definitions in Self-Serving Assessments of Ability, in HeURIstics AND BIASES: THE PSYCHOLOGY OF INTUITIVE JUDGMENT, supra note 39 , at 324, 325-33. The tendency may be magnified when evaluating bargaining skill. Most individuals describe themselves as good bargainers even when their actual performances fall short of their expectations. LEIGH L. THOMPSON, THE MIND AND HEART OF THE NEGOTIATOR 5 (3d. ed. 2005). Even professionals who negotiate for a living fall prey to this overconfidence, both overestimating their ability to adhere to strategies and underestimating the probability that something will go wrong. Id. at 5, 27, 193.

98. They might think, for example, that they should never display weakness or lack of conviction in the face of aggression and assume that they always behave in that way, ignoring experiences or personal character traits that might make such an assumption implausible. 
circumstances and, without anyone to disagree, are free to assume that their thoughts are mothers to their deeds. ${ }^{99}$ It is not surprising that they would give "correct" answers to survey questions; they would have to think themselves incompetent to do otherwise. It would be a mistake to indulge them in this assumption, however, or to take their responses at face value. For the most part, subjects in Prospect Theory research are not trained empiricists; they do not have any particular skill at examining behavior systematically, ${ }^{100}$ on the basis of direct data, ${ }^{101}$ with an understanding of how intentions and expectations do not always shape behavior. ${ }^{102}$ To learn how they truly bargain one would have to observe them doing it - arguing, trading, threatening, brainstorming, compromising, agreeing and the likeunder real life conditions and with real life stakes, where they would fall back on the skills and habits internalized in past bargaining experiences and social relationships generally. Events would move too quickly for them to do anything else.

Given these important differences between Prospect Theory research and real life bargaining, the claim of some legal bargaining theorists - that lawyer bargainers often are susceptible to the influence of irrational heuristics and biases - seems premature, if not circular. ${ }^{103}$ If Prospect

99. In Prospect Theory parlance, they are free to indulge in a confirmatory bias. See Gretchen B. Chapman \& Eric J. Johnson, Incorporating the Irrelevant: Anchors in Judgments of Belief and Value, in Heuristics AND Biases: THE Psychology OF InTUitive Judgment, supra note 39, at 120,133 (Confirmation bias is the tendency "to seek information that $\mathrm{i}[\mathrm{s}]$ consistent with the current hypothesis and ... to interpret evidence as consistent with the hypothesis ...."); Derek J. Koehler, Lyle Brenner \& Dale Griffin, The Calibration of Expert Judgment: Heuristics and Biases Beyond the Laboratory, in HEURISTICS AND BIASES: THE PSYCHOLOGY OF INTUITIVE JUDGMENT, supra note 39, at 686, 692 ("According to the confirmatory bias model ... [there is] a general tendency ... to recruit reasons from memory that confirm the focal hypothesis.") (citation omitted). The overconfidence bias, see Dale Griffin \& Amos Tversky, The Weighing of Evidence and the Determinants of Confidence, in HeuRISTICS AND BIASES: THE PSYCHOLOGY OF INTUITIVE JUDGMENT, supra note 39, at 230, 230-39 (describing the "determinants of confidence"), and availability heuristic, see Tversky \& Kahneman, supra note 48, at 1127-28, also help explain such reports.

Although individuals often fail to identify accurately all of the influences on their judgments and decisions, and thus fail to be conscious of biasing influences on their judgments and decisions, they may nonetheless engage in deliberations due to the nature of the task confronted without any extra situational prompting or special internal predispositions to do so.

But see Mitchell, Second Thoughts, supra note 56, at 18-19.

100. But see Amos Tversky \& Daniel L. Kahneman, Belief in the Law of Small Numbers, 76 PSYCHOL. BULL. 105 (1971) (study in which subjects were "experienced research psychologists").

101. Chris ARgYris \& DONALD A. SCHÖn, TheORY IN PRACTICE: InCREASING PROFESSIONAL EFFECTIVENESS 38-40 (1974).

102. Id. at 6-7 (defining theories in action), and 174-80 (describing "incongruities . . between espoused theories and theories-in-use").

103. Mitchell describes behavioral decision theory as producing: 
[Vol. 10: 2, 2010]

PEPPERDINE DISPUTE RESOLUTION LAW JOURNAL

Theory data shows that bargainers reason irrationally, and it is not yet clear that it does, ${ }^{104}$ it might be because Prospect Theory experiments do not embody the principal mechanism built into real-life bargaining to correct for irrationality, that of another bargainer arguing the opposite side. ${ }^{105}$ In a sense, absolving subjects from the need to justify demands and explain positions to adversaries almost invites them to be irrational, or at least to act as if they were in unilateral control of the situation and under no obligation to consider other viewpoints or entertain alternative outcomes. ${ }^{106}$ In the end, real life bargaining and Prospect Theory research are different in kind-one is dialogue and the other monologue $\mathrm{e}^{107}$-and this difference warrants a certain cautiousness in extrapolating from one to the other. It would be ironic if research noted for its criticism of the empirical foundations of

a mythology of decision making as rampantly and fundamentally flawed ... through the repeated use of standard research paradigms that are designed to show biased behavior and through the use of statistical methodology that stacks the deck in favor of finding biased behavior without concern for the practical importance of the behavior outside of the laboratory and, perhaps most surprisingly, largely without documenting that any particular individuals actually acted irrationally in the experiments.

Cf. Mitchell, Taking Behavioralism Too Seriously?, supra note 24, at 1946

104. Tversky and Kahneman seem to think that such judgments are departures from rationality. See Tversky \& Kahneman, supra note 48, at 1124 (describing the heuristics as "quite useful, but sometimes they lead to severe and systematic errors"); Kahneman, Maps, supra note 33, at 1469 ([T]he problem "is not that they reason poorly but that they often act intuitively... [their] behavior ... is not guided by what they are able to compute, but by what they happen to see at a given moment."); KeITH E. STANOVICH, WhO Is RATIONAL? STUDIES OF INDIVIDUAL DifFERENCES IN REASONING 252 (1999) (After reviewing the most important heuristics and biases experiments they conclude that "[i]t does seem that some human behavior is systematically irrational."). But see Gerd Gigerenzer \& Daniel G. Goldstein, Betting on One Good Reason: To Take the Best Heuristic, in SimPle HeURISTICS THAT MAKE US SMART, supra note 49, at 75-95 (analyzing the judgment heuristic of "Take the Best").

105. Think of this as a structural "outside strategy." Trout, supra note 48, at 420-21 (describing outside strategies). See also Mitchell, Second Thoughts, supra note 56, at 12 ("conscious awareness of bias is not a necessary precondition to self-correction."). An adverse bargainer can be thought of as a kind of "accountability mechanism" in Mitchell's felicitous term. Id. at 39 ("[E]recting accountability mechanisms that encourage metacognitive reflection and possibly doubt about the neutrality or legality of one's decisions may debias judgments in legally sensitive or risky situations ....").

106. Mitchell, Second Thoughts, supra note 56, at 14 ("Bias avoidance occurs also because some situations prompt debiasing deliberative thought across a wide range of people, such as the self-critical reflection prompted by knowledge that one's judgments and decisions must be explained to an audience with unknown views.") (footnote omitted).

107. Professor Korobkin describes the typical experiment as investigating "how lawyers and law students think about issues that arise in negotiation concerning lawsuits and potential lawsuits." Korobkin, supra note 37, at 36-37. 
expected utility analysis ended up being used in an empirically questionable manner itself, but then irony has become so commonplace in modern life that it is almost obsolete. ${ }^{108}$

\section{B. Prospect Theory Data is About Students and Not Lawyers}

Prospect Theory research does not study lawyer bargainers directly. Studying lawyers would be expensive, time consuming, and cumbersome. Real life legal bargaining does not follow easily manipulated timetables, lend itself to having variables controlled or background facts held constant, and lawyers do not work for pennies, pastries, or vouchers to fast food restaurants. ${ }^{109}$ Even if these and other such practical difficulties could be overcome, lawyers and clients are not likely to consent to being studied-the former to protect their strategies and the latter their privacy-and such studies could not proceed without their consent. For these reasons, and also because it is interested in decision making generally, not lawyer bargaining decision making in particular, Prospect Theory research is based mostly on college student responses to hypothetical decision problems distributed usually at the beginning of psychology class. ${ }^{110}$

108. One is reminded of Tom Lehrer's supposed reaction to the news that Henry Kissinger had been awarded the Nobel Peace Prize: that "satire was now obsolete." See Stephen Thompson, Interview with Tom Lehrer, http://www.avclub.com/content/node/22863 (last visited Oct. 11, 2009).

I don't know how that got started. . . . For one thing, I quit [doing satire] long before that happened, so historically it doesn't make any sense. I've heard that quoted back to me, but I've also heard it quoted that I was dead, so there you are. You can't believe anything you read.

Id.

109. See infra notes 234-239 and accompanying text. I come back to this topic at the end of the article when I discuss the characteristics of future research on legal bargaining. There, I suggest that anthropological studies, such as those in books like A Civil Action, Peter Schuck's Agent Orange on Trial, and the like, provide the best examples of real life negotiation data. That such books are in short supply gives one a sense of how difficult the data is to collect.

110. Prentice, Chicago Man, supra note 24, at 1713 n.264. See also Korobkin, supra note 37, at 36-37 (describing an experiment in which law students in Business Association and Negotiation courses were asked questions during the first week of class about how they would act in hypothetical bargaining decision scenarios); Mitchell, Why Law and Economics, supra note 33, at 156 ("[C]ollege-age adults ... serve as the subjects of the vast majority of behavioral decision theory research."); JONATHAN BARON, THINKING AND DECIDING 49 (4th ed. 2008) ("Psychologists often use what others call (somewhat derisively) 'convenience samples,' such as students enrolled in an introductory psychology course."). In addition to college students, Prospect Theory experiments have involved research psychologists and statisticians, see Tversky \& Kahneman, supra note 48, at 1125,1130 , as well as graduate students, business executive, doctors, realtors, auditors, financial traders, and federal judges. See Prentice, Chicago Man, supra note 24, at 1726-29 (listing the various types of subject populations used in Behavioral Decision Theory research); Guthrie \& Rachlinski, supra note 40, at 2021-22 (listing the various types of subject populations used in Behavioral Decision Theory research); Chris Guthrie, Jeffrey J. Rachlinski \& Andrew J. Wistrich, 240 
[Vol. 10: 2, 2010]

PEPPERDINE DISPUTE RESOLUTION LAW JOURNAL

This data might be an appropriate basis for the study of decision making in general; ${ }^{111}$ but students solving stylized, academic, low-stakes, strategy puzzles, usually for the first time, ${ }^{112}$ are engaged in an altogether different enterprise from that of lawyers settling real life disputes. Lawyers are experienced at bargaining and experienced actors are less susceptible than novices to the heuristics and biases of imperfect rationality. ${ }^{13}$ Prospect Theory research itself establishes this. ${ }^{114}$ Student subjects, in comparison,

Inside the Judicial Mind, 86 CORNELL L. REV. 777 (2001) (describing a study in which judges were subjects). The use of student subjects could be an instance of Prospect Theory research falling victim to its own form of an "availability bias." See David O. Sears, College Sophomores in the Laboratory: Influences of a Narrow Data Base on Social Psychology's View of Human Nature, 51 J. PERSONALITY \& SOC. PSYCHOL. 515 (1986) (describing the limitations of student subject populations); Reginald Smart, Subject Selection Bias in Psychological Research, in THE SCIENCE OF PSYCHOlOGY: CRITICAL REFLECTIONS 155, 155-61 (Duane P. Schultz ed., 1970) (describing the limitations of student subject populations).

111. But see Mitchell, Why Law and Economics, supra note 33, at 139-60 (describing the range of individual differences in subject populations that must be taken into account in developing a general theory of legal decision making).

112. Prentice, Chicago Man, supra note 24, at 1698-99 (suggesting that students who have not previously participated in social science research projects make the best subjects). Professor Prentice points out that "psychologists in the heuristics and biases school tend to study one-shot decisions [whereas] experimental economists tend to create markets and allow subjects to play repeatedly ...." Id. at 1703 .

113. Kahneman, Maps, supra note 33, at 1453 ("[T] skill gradually increases the accessibility of useful responses and of productive ways to organize information, until skilled performance becomes almost effortless."); BRAIN, MIND, EXPERIENCE, AND SCHOOL 31 (John D. Bransford et al. eds., 2000) ("Experts notice features and meaningful patterns of information that are not noticed by novices."); Babcock et al., supra note 82, at 294-95, 300-01 (describing how student and lawyer subjects make different predictions about adjudicated outcome and estimates of client reservation prices because of their different experiences with lawyer roles); Russell Korobkin \& Chris Guthrie, Psychology, Economics, and Settlement: A New Look as the Role of the Lawyer, 76 TEX. L. REV. 77, 100 (1997) (finding that attorney subjects preferred certain settlement over the option of risky litigation with a lower expected value). Some Prospect Theory experiments are based on highly unusual and emotionally charged events with which most adults, let alone students, would have little direct experience, and in which they would want to consult with family and friends before deciding how to respond. See, e.g., Chapman \& Bornstein, supra note 77, at 523-24 (describing an anchoring experiment involving a personal injury lawsuit "in which ... a young married woman named Kathy, sued her health-maintenance organization...., claiming that the birth control pill they [sic] prescribed caused her to develop ovarian cancer."). To assume that an instantaneous student resolution to such a problem, arrived at after reading a "onepage description" of the events is the equivalent of a fully considered adult responses, both intellectually and emotionally, seems optimistic at best. Id. at 523 .

114. John A. List, Does Market Experience Eliminate Market Anomalies?, 118 Q.J. ECON. 41 (2003) (describing how experienced traders are less reluctant to exchange one set of goods for another because they have learned to base their decisions on long term value rather than the immediate emotions associated with getting or giving up objects); Weinstein, supra note 31 , at 820 241 
have limited experience with social science research problems and are often selected for just that quality. ${ }^{115}$ Also unlike students, lawyers have internalized the habits, conventions, and values of a professional practice, both those of the particular professional communities in which they work and the legal profession in general. ${ }^{116}$ Lawyers make decisions as agents, not principals. ${ }^{117}$ They define objectives and construct strategies from the perspective of client interests rather than their own, and push aggressively for outcomes they would not always pursue if it was up to them

(describing how lawyers and judges are less sensitive to framing biases because they "have learned to think about and analyze expected value. ... Their repeated exposure to problems of this sort ... helps them develop the habit of analyzing these problems in economic terms"); Korobkin \& Guthrie, supra note 113, at 99-101 (suggesting that lawyers are less susceptible than non-lawyers to framing effects in settling a hypothetical personal injury claim); Rachlinksi, supra note 26, at 757 (describing how "novices in a field or one-shot players are unlikely to have had enough experience to have received adequate feedback" about their cognitive biases to avoid errors in judgment.); Guthrie \& Rachlinski, supra note 40, at 2025 (describing how "insurance professionals demonstrated an impressive ability to resist the problems that heuristics can cause ... [and] behave more like homo economicus than homo psychologicus"). Decision making in real life bargaining differs from student game playing in another significant respect. Lawyer bargaining decisions almost invariably are reviewed, both by other lawyers and clients, before they become final. These additional layers of review add experience, accountability, and perspective to the decision process and make it even less like a spontaneous and unmonitored, single-student reaction in a psychology class. See Jennifer S. Lerner \& Philip E. Tetlock, Accounting for the Effects of Accountability, 125 PSYCHOL. BULL. 255 (1999); Mitchell, Why Law and Economics, supra note 33, at 110 (describing how "[a]ccountable and unaccountable decisionmakers often act differently"); Richard P. Larrick, James N. Morgan \& Richard E. Nisbett, Teaching the Use of Cost-Benefit Reasoning in Everyday Life, 1 PSYCHOL. SCI. 362, 369 (1990) (“'A]lthough people ordinarily are not perfectly rational by economists' standards, they are capable of becoming more rational."). But see Prentice, Chicago Man, supra note 24, at 1746 (arguing that the issue of whether subjects in laboratory experiments are less accountable than real world actors is "unresolved") ("Even college students, who are more likely to be irresponsible in participating in such . . . experiment[s] . . . have generally been found to be 'a fairly good proxy for real people."') (quoting Chris Guthrie, Prospect Theory, Risk Preference, \& the Law, 97 Nw. U. L. REV. 1115, 1156 (2003)). Id. at 1713 n.264.

115. The lack of experience is seen as a desirable trait in experimental subjects. See Prentice, Chicago Man, supra note 24, at 1698.

116. See generally Geoffrey C. Hazard, Jr., The Lawyer's Obligation to be Trustworthy when Dealing with Opposing Parties, 33 S.C. L. REV. 181, 193-94 (1981) (describing differences between big city and small town bargaining practices); Thomas F. Guernsey, Truthfulness in Negotiation, 17 U. RICH. L. REV. 99, 103-21 (1982) (listing bargaining conventions); Geoffrey M. Peters, The Use of Lies in Negotiation, 48 OHIO ST. L.J. 1, 7, 13 (1987) (describing the conventions of lawyer negotiators allowing intentional deception but prohibiting outright lies); MODEL RULES OF PROF'L CONDUCT R. 4.1 cmt. 2 (1983) (describing "generally accepted conventions in negotiation"); William H. Simon, The Trouble with Legal Ethics, 41 J. LEGAL EDUC. 65, 66-67 (1991) ("The law of negligence holds professionals to a 'standard of care' that represents a set of collectively defined but uncodified and partially unwritten general norms whose application to particular situations is assumed to require the reflective judgment of a qualified practitioner.").

117. Mitchell, Why Law and Economics, supra note 33, at 161-64 (reporting studies that find that persons acting as agents do not always make decisions in the same way as persons acting as principals). 
[Vol. 10: 2, 2010]

PEPPERDINE DISPUTE RESOLUTION LAW JOURNAL

personally. ${ }^{118}$ They understand how correct results can be the work of systems rather than self-authorizing individuals, and how forcing adversaries to the limits of their authority can often be the best test of what their clients are entitled to receive. ${ }^{119}$ Students bring the distinctively different values and beliefs of young adults to Prospect Theory experiments and this makes the patterns in their behavior a questionable foundation on which to build a prescriptive theory of lawyer bargaining.

\section{Prospect Theory Is About Form and Not Substance}

Prospect Theory's almost exclusive focus on the form of decision making, rather than its underlying substantive reasons, makes the theory an awkward tool for studying a process that depends on the assessment of competing substantive claims for its legitimacy. ${ }^{120}$ Prospect Theory has no standards for sorting true arguments from false ones, fair resolutions from unfair ones, sociable behavior from unsociable behavior, efficient outcomes from inefficient ones, and the like. ${ }^{121}$ It simply is not a substantive theory of any kind. ${ }^{122}$ In this respect, it is the latest and most sophisticated example of

\footnotetext{
118. Id.

119. Malhotra \& Bazerman, supra note 32, at 525 (describing why "in many cases, negotiators do want to claim as much as possible").

120. See Adler, supra note 39, manuscript at 14-15.

121. See id.

122. See id. Matthew Adler discusses this point in considering whether Prospect Theory can combine with expected utility theory to provide a normative account of decision making by rationally bounded actors. See id. Adler argues that Prospect Theory is:

[J] ust orthogonal to that question. It tells the decisionmaker to transform outcomes into

losses and gains from a reference point, and to transform the probabilities of states by an

$\mathrm{S}$-shaped function. How to characterize outcomes in the first place ... and which actions

to consider, ... are not parts of the theory.

$I d$. manuscript at 15 . Giving a general normative account of decision making by rationally bounded actors, Adler argues, is a "problem that no one has yet managed to solve." Id. But see Rachlinski, supra note 26, at 754 (arguing that Behavioral Decision Theory can combine with traditional legal norms (e.g., "treat like cases alike") to suggest normative positions and "the prescriptive norm [in Behavioral Decision Theory] is clear-eliminate error in judgment"). See also Mitchell, Taking Behavioralism Too Seriously?, supra note 24, at 1939 ("The norms that serve as the criteria for rational behavior in behavioral decision theory emphasize the internal coherence and logical consistency of decisions and judgments."). Rachlinksi acknowledges that judgment errors can have beneficial effects, and that when they do,

[Behavioral Decision Theory] does not provide a clear normative position. The best that

[it] can do ... is to identify, and perhaps quantify, the costs and benefits of the cognitive

processes. The question of whether to implement legal reforms that make people
} 243 
a long line of procedural systems used by some legal bargaining theorists to minimize, if not eliminate, the role of substantive argument in the settlement of legal disputes. ${ }^{123}$ Many bargaining scholars believe that constructing individualized and ad hoc standards for resolving disputes is empowering - a way for parties to take responsibility for and control over their lives - and they see resorting to external standards, including legal rules, as a kind of abdication of this responsibility. ${ }^{124}$ Unfortunately, because the disagreements at the root of legal disputes are governed by law, it usually is not possible to resolve those disputes without examining the merits of the parties' competing legal claims. Prospect Theory may contribute to an

unhappy but lead them to make more efficient decisions must be answered in some other way.

Rachlinski, supra note 26, at 760. See also Jolls, Sunstein \& Thaler, supra note 46, at 1541 (describing the normative content of behavioral decision theory as "anti-antipaternalism").

123. See, e.g., Max H. Bazerman, Negotiator Judgment: A Critical Look at the Rationality Assumption, 27 AM. BEHAV. SCIENTIST 211, 220-25 (1983) (describing the process of influencing an adverse negotiator as consisting of trading proposals, framing issues, and making leveraging moves); Malhotra \& Bazerman, supra note 32, passim (describing the process of influencing an adverse negotiator as consisting of trading proposals, framing issues, and making leveraging moves). Influencing a bargainer to change his "attitude towards a given idea or proposition," say Malhotra and Bazerman, typically entails "leveraging an understanding of psychological biases and heuristics [in order] to frame ideas and proposals in such a way that increases their appeal." Id. at 512. The authors' lack of interest in normative argument is probably explained by the fact that they write mostly about transactional bargaining and not dispute settlement. See id. at 511-12. Korobkin and Guthrie, on the other hand, seem to view the use of heuristics and biases to manipulate adverse bargainers as interchangeable with normative argument:

In litigation bargaining, the settlement versus adjudication decision rests in large part on the negotiator's judgment of what a court would award the plaintiff should settlement negotiations fail. Because adjudication results are notoriously difficult to predict, the plaintiff's lawyer has a clear opportunity to improve his chances of convincing the defendant to choose settlement at a favorable price over adjudication (and vice versa for the defendant's lawyer) by manipulating the defendant's judgment of the adjudication option. Of course, the plaintiff's lawyer might accomplish this by persuasive argumentation. He might also accomplish this, however, by exposing the defendant to a high anchor-perhaps by making a very high initial settlement demand. Even if the defendant immediately rejects the high demand out of hand, the demand could anchor the defendant's prediction of a jury verdict, making that judgment higher than it otherwise would be, and thus increasing the likelihood that the defendant would choose a somewhat lower settlement demand over the adjudication alternative.

Korobkin \& Guthrie, supra note 40, at 805-06.

124. See, e.g., Carrie Menkel-Meadow, Toward Another View of Legal Negotiation: The Structure of Problem Solving, 31 UCLA L. REV. 754, 817 (1984) ("There is nothing in the problemsolving model [of negotiation] which necessarily compels parties to consider the justice of their solutions ....") (When "the parties have widely divergent views ... one of the primary advantages [of problem-solving negotiation] is that no judgment need be made about whose argument is right or wrong."). Id. at 826; FISHER, URY, \& PATTON, supra note 85, at 22 ("Ultimately, however, conflict lies not in objective reality, but in people's heads. Truth is simply one more argument-perhaps a good one, perhaps not—for dealing with the difference."). 
[Vol. 10: 2, 2010]

understanding of this process at the margins, but it does not say anything about it directly, and the attempts by legal commentators to make the necessary extrapolations have proven to be disappointing. ${ }^{125}$

Even as a system of strategic maneuvering, Prospect Theory may not have much to offer legal bargaining. Two bargainers equally skilled at Prospect Theory techniques would be a sight to behold. Unlike their adversarial counterparts trying scrupulously to avoid making the first offer, for example, "prospectors" would take the initiative, thrusting and parrying with enthusiasm and energy, in a sort of reverse Alphonse and Gaston, relentlessly neutralizing one another's efforts in a flurry of framing, anchoring, devaluing, saliencing, and the like, all while staying substantively in place. ${ }^{126}$ The reason for this is simple enough. People are able to recognize and avoid the decision errors identified by Prospect Theory once they are alerted to them. ${ }^{127}$

In the end, Prospect Theory's focus on the outward form of decision making rather than its underlying mechanics, its failure to consider the role of professional socialization and practice skill in the exercise of judgment, its isolation of decision making from the institutional settings and practical constraints within which it operates, and its reliance on data which excludes

125. Mitchell argues that certain legal decision theorists:

[E]ngage in a fair amount of extrapolation from findings in nonlegal settings to the likely effects in legal settings. [Some of these theorists] acknowledge this practice and acknowledge that it is not ideal. The freedom in such extrapolations is of course great. Unfortunately, what seems to have happened so far is that the legal decision theorists have only included in their behavioral theorizing those empirical studies that support their views and have ignored and downplayed those studies that contradict their views.") (citations omitted).

See Mitchell, Why Law and Economics, supra note 33, at 122-23 n.170.

126. Malhotra \& Bazerman, Psychological Influence, supra note 32, at 522-25 (describing "defense[s] against psychological influence tactics" based on Behavioral Decision Theory insights).

127. Stein, supra note 89, at 536-37. Alex Stein describes how Prospect Theory experiments fail to distinguish between cognitive performance and cognitive competence. Id. The experiments establish that subjects err in their probability calculations (but only when judged against a narrow economic conception of rationality), and not that they are cognitively incompetent to make such calculations. Id. If people remain cognitively competent even when they err, they can learn to avoid error when properly alerted to it. Id. at 538. "Admittedly," as Stein says, "people often fall into traps set by [Prospect Theory] experimenters in order to test their rationality. Id. These traps, however, can only function as the conjurer's sleight of hand: each trick can be played only once. ... $[T]$ he play uncovers and thereby destroys the trick." Id. See also Guthrie \& Rachlinski, supra note 40, at 2022 ("Our data suggest that insurers might have developed cognitive skills that enable them to avoid many common errors in judgment that appear to plague other actors during the litigation process."). 
or simplifies many of the important dimensions of real life decision making, all in the absence of any genuine adversarial context, means that it may not have much to contribute, even by extrapolation, to the task of understanding and improving legal dispute bargaining. Judged on its stand-alone merits, therefore, there is reason to be skeptical about the prospects of a Prospect Theory based effort to reconceptualize legal bargaining. These are concerns about Prospect Theory in general, however, and not necessarily about particular Prospect Theory concepts or findings. Like economics, Prospect Theory may have useful prescriptive advice to give to legal bargainers even if the advice is grounded in an inaccurate empirical understanding of legal bargaining. ${ }^{128}$ To consider whether this is so, I will examine the Prospect Theory concept of anchoring and adjustment. Of all the Theory's concepts, anchoring is the one most directly connected to bargaining outcome and the one most thoroughly discussed in the legal bargaining literature. It is (or was) $)^{129}$ a central element in the Prospect Theory model of decision making and judgment. If the examination of anchoring and adjustment does not provide useful insights into the nature of legal bargaining, there is reason to be pessimistic about the contributions of Prospect Theory as a whole.

\section{ANCHORING DESCRIBED}

Anchoring is the process of estimating value by starting from an initial value, usually the first number encountered in a discussion, and adjusting from that value until reaching a final or target estimate. ${ }^{130}$ It is an automatic process that operates outside the awareness of the person doing it. ${ }^{131}$ An initial value "may be suggested by the formulation of the problem, or it may

128. See Milton Friedman, The Methodology of Positive Economics, in ESSAYS IN POSITIVE ECONOMICS 3, 14-16 (1953) (arguing that false assumptions about real world conditions are unimportant as long as they predict correct results); Daniel M. Hausman, Economic Methodology in a Nutshell, J. ECON. PERSP., Spring 1989, at 115, 119 (analyzing Friedman's approach to economics as "predictionism"); Andrew Brod, Economics as One of the Humanities: A Comment, 4 S. CAL. INTERDISC. L.J. 313, 316 (1995) ("For economists, rationality is first and foremost a useful assumption, useful because it helps them build models that happen to predict human behavior quite well ....”). Judge Posner's well known textbook also defends economics in terms of its predictive and explanatory power rather than its descriptive accuracy. See Richard A. POSNER, ECONOMIC ANALYSIS OF LAW 17-18 (6th ed. 2003).

129. But see supra note 49 for a description of the debate over whether anchoring is fundamental.

130. See Orr \& Guthrie, supra note 36, at 599-600; Tversky \& Kahneman, supra note 48, at 1128; Korobkin \& Guthrie, supra note 40, at 799-800.

131. See Rachlinski, supra note 26 , at 751 ; Tversky \& Kahneman, supra note 48 , at 1128 . See also Prentice, Chicago Man, supra note 24, at 1717 (describing anchoring's role in Kahneman \& Tversky's System 1/System 2 Prospect Theory framework).

246 
[Vol. 10: 2, 2010]

be the result of a partial computation,"132 but whatever its source, adjustment from it typically results in a final estimate biased in its favor. ${ }^{133}$ Anchoring does not occur automatically whenever a number is randomly mentioned. A listener must give the number sufficient attention. ${ }^{134}$ For this to happen the number must relate to the target value in some way, or have what the Prospect Theory calls "anchor-target compatibility." 135 The most common negotiation anchor is the opening offer or demand, but insurance policy limits, statutory damage caps, negotiator aspirations, and other "first numbers" can be anchors as well. ${ }^{136}$ Relying on anchors is not invariably bad, as sometimes the first number encountered in thinking about a problem is a useful benchmark for determining the problem's eventual resolution. However, irrelevant or uninformative information can be an anchor as well, and when it is, it can distort the decision process and cause bargainers to make unwise judgments. ${ }^{137}$

While anchoring is endemic to dispute settlement generally, most agree that it exercises its greatest influence in private negotiation where the lack of public monitoring permits it to operate relatively unchecked. ${ }^{138}$ For many legal bargaining theorists, in fact, anchoring is now a basic truth of bargaining, ${ }^{139}$ and one that overrides traditional bargaining rules of thumb with which it conflicts. ${ }^{140}$ For example, proponents of anchoring reject the

132. Tversky \& Kahneman, supra note 48 , at 1128.

133. Id. at 1128; Orr \& Guthrie, supra note 36, at 602.

134. Chapman \& Johnson, supra note 99, at 123.

135. Id. at 123-24. Chapman and Johnson give the example of an experiment in which different groups of subjects were asked to estimate the height or width of the Brandenburg gate. Id. Each group was given a random number that expressed the dimension of height or width, but those who were given a number of the same dimension as the one they were asked to provide (i.e., a number with anchor-target compatibility), showed a greater propensity to anchor on the number than those who were given a number of a different dimension. Id. (citing Strack \& Mussweiler, supra note 39).

136. Orr \& Guthrie, supra note 36 , at 598.

137. Korobkin \& Guthrie, supra note 40, at 799 ("[I]ndividuals sometimes anchor on values that are largely, or even completely, irrelevant.”); Guthrie \& Rachlinski, supra note 40, at 2033 ("several studies show that truly preposterous anchors influence judgment").

138. See Orr \& Guthrie, Anchoring, supra note 37, at 609 ("[A]nchoring ... may be even more insidious [at the bargaining table] than in the courtroom because negotiation is so much more common than adjudication ... [it thus] may lead to much more inefficiency and inequity ....").

139. Orr \& Guthrie, supra note 36, at 598 ("[W]e find that anchoring has a powerful impact on negotiation outcomes."); Korobkin \& Guthrie, supra note 40, at 799 ("To estimate the value of an option, negotiators are likely to start with the value of a known option, the 'anchor,' and then adjust to compensate for relevant differences in the character of the known and unknown item.").

140. Orr and Guthrie, supra note 36, at 598. 
"never make the first offer" principle, arguing instead that a bargainer always is better off making an aggressively high first offer even when he does not expect it to be taken literally or be the specific proposal on which the parties ultimately agree. ${ }^{141}$ The reason is simple. Settlement invariably falls between the parties' initial offers - one does not usually receive more than is requested or give more than is demanded ${ }^{142}$ - and an aggressively high first offer imbalances the bargaining range in one's favor (or neutralizes the adversary's attempt to do the same). ${ }^{143}$ When the parties divide the range roughly in half, as almost invariably they will, ${ }^{144}$ this guarantees that the party with the comparatively higher first offer will win a disproportionate share of the items in dispute. ${ }^{145}$ This dynamic can dominate even the substantive strengths and weaknesses of the parties' claims. ${ }^{146}$ Bargainers with high aspirations and weak cases can outperform bargainers with low aspirations and strong cases, ${ }^{147}$ or so Prospect Theory based bargaining theory has it. ${ }^{148}$

How anchoring works this magic is open to debate. ${ }^{149}$ The so-called social implications theory ${ }^{150}$ holds that bargainers rely on the information in anchors because they believe it will be helpful; that others would not volunteer the information if that were not the case. Here, the operative (and problematic) concept seems to be that of warranted belief, not anchoring. Someone who accepts information as reliable simply because another person

141. ThOMPSON, supra note 97, at 49 ("Distinct advantages are associated with making the first offer in a negotiation."); Orr \& Guthrie, supra note 36, at 624-25. This is just one of the many ways in which a Prospect Theory based conception of legal bargaining differs from a communitarian conception of bargaining. See Condlin, supra note 92, at 1-2 n.3 (describing communitarian conception of bargaining). The Prospect Theory's concept of de-biasing is another example. Asking a bargainer to "consider the opposite" in assessing the anchor value of an offer assumes that the offer will be contested and that there always will be something to be said for the other side. See infra notes 206-07 and accompanying text for a discussion of the strategy of "consider the opposite." Communitarians often assume that bargainers on both sides have the same interest. Condlin, supra note 92 , at $1-5$.

142. THOMPSON, supra note 97 at $47-48$.

143. Id.

144. Winning and losing is obvious if the parties do not divide the range in a roughly equal fashion and few bargainers are willing to lose in an obvious fashion.

145. THOMPSON, supra note 97, at 47-48. Both sides cannot act on this advice, of course, just as they cannot both act on the traditional advice to "never make the first offer." Many bargaining rules of thumb assume the presence of a less skilled adversary.

146. Id.

147. ThOmpson, The Mind And HeART, supra note 97, at 47-48.

148. Id.

149. I take my organization of this section of the discussion from Orr and Guthrie. See Orr \& Guthrie, supra note 36, at 598-606.

150. Id. at 602 . 
[Vol. 10: 2, 2010]

PEPPERDINE DISPUTE RESOLUTION LAW JOURNAL

has provided it has an incomplete understanding of the concept of warranted belief. The "insufficient adjustment theory" "failure to adjust" away from the anchor. ${ }^{152}$ This explanation begs the question, of course, ${ }^{153}$ since one must then ask why people fail to adjust. Orr and Guthrie's patch, that a failure to adjust is explained by a "lack of cognitive effort," in life, but not in a way that advances understanding or provides direction about how to proceed.

The "numeric priming theory" 155 argues that the first number mentioned in thinking about a problem has a "priming" 156 effect on a person's decision making process independent of the number's relevance. The number's increased salience as a consequence of being mentioned first makes it more accessible to the listener in the hypothesis testing process that leads to judgment, and thus gives it a greater influence on the outcome of that judgment. ${ }^{157}$ As Strack and Mussweiler put it, "[I]f we have to make judgments under suboptimal conditions, we are particularly likely to use what is at the top of our minds as a basis of our judgments." ${ }^{158}$ That a first

151. Id. at 602-03.

152. Chapman \& Johnson, Incorporating the Irrelevant, supra note 99, at 120, 127.

153. Orr \& Guthrie, supra note 36, at 603.

154. Id. at 603 (citing Chapman \& Johnson, supra note 99). See also Guthrie \& Rachlinski, supra note 40, at 2026 (failure to adjust away from an anchor caused by "cognitive laziness").

155. Orr \& Guthrie, supra note 36, at 603-04.

156. Strack \& Mussweiler, supra note 39 , at 81 (“[The] mechanism of 'numeric priming' ... is based exclusively on mechanisms of increased [information] accessibility."). The concept of "priming" analogizes the hydraulic process of preparing a mechanical device for operation by pouring a liquid into it (e.g., water into a pump, gasoline into a carburetor), to the intellectual and emotional process of preparing a bargainer to look favorably upon a demand by mentioning that demand early in the beginning conversation (pouring it into the other bargainer's head, so to speak). Since ideas and emotions are not hydraulic, the concept of "priming" seems more an evocative metaphor than an analogy, but Strack and Mussweiler also describe the cognitive process through which an anchor number leads to judgment. $I d$. at 80-83.

157.

That is, even though the possibility that a target possesses the property implied by the standard is rejected and qualified, information that is consistent with this possibility will be activated and thereby be more accessible for subsequent use. As a consequence, the absolute judgment will be assimilated toward the standard of comparison.

Id. at 82. Strack and Mussweiler acknowledge that "[u]nless [a number value] is associated with a semantic dimension, it is difficult to conceive how [it] can by itself become the basis of a judgment," but argue that "abundant research demonstrating [that] such semantic [content] influences [judgment] suggests that a similar mechanism may also be responsible for assimilation effects in the anchoring paradigm." Id. at 81 .

158. Id. at 80 . 
number should be influential simply because it is first is not a self-evident proposition, however, particularly in bargaining where first numbers are routinely exaggerated and known to be so. Strack and Mussweiler do not discuss this complication. ${ }^{159}$

Finally, "the most widely accepted explanation of anchoring,"160 the "information accessibility theory," 161 holds that an anchor has weight because thinking about it gives it weight, and that one cannot help thinking about it once it is mentioned. On this view, the information in an anchor is influential because it is "salient," "accessible," or "available," and sometimes the only information one has. ${ }^{162}$ This explanation seems difficult to distinguish from the numeric priming view and is subject to the same objection. Whatever the explanation, however, and each of the above efforts falls short in one respect or another, most legal bargaining theorists agree that "the number that starts the generation of a judgment exerts a stronger impact [on that judgment] than do subsequent pieces of numeric information." 163

Perhaps the most venerable illustration of the power of anchoring, and a favorite of legal bargaining theorists, ${ }^{164}$ is the so-called African Countries in the United Nations experiment conducted by Kahneman and Tversky in the

159. Strack and Mussweiler discuss the role of anchoring in conversation only briefly, and then only to describe studies of the Gricean Maxim of Quantity (requiring "people to find the right level of specificity for their contributions to a conversation"). Id. at 90 (citing H. Paul Grice, Logic and Conversation, in 3 SyntaX And Semantics: SPEECH ACTS 41 (Peter Cole \& Jerry L. Morgan eds., 1975)). They focus principally on how "[vague verbal quantifiers] are calibrated by 'anchoring' the reference system of a communicator and by establishing an ordinal structure of targets on a response scale," but do not say how anchoring can be used adversarially to shape another party's calculation of value. Id. See also Daniel Kahneman \& Amos Tversky, On the Study of Statistical Intuitions, 11 COGNITION 123, 135 (1982) ("We conclude that the conversational aspect of judgment studies deserves more careful consideration than it has received in past research, our own included."); Mitchell, Taking Behavioralism Too Seriously?, supra note 24, at 1980-84 (describing developments in heuristics and biases research since the work of Kahneman and Tversky focused on "experimental conversations").

160. Orr \& Guthrie, supra note 36, at 604.

161. Id. at 604-05.

162. In this sense, it is not clear how this explanation differs from the numeric priming theory. Each seems to be a different formulation of the idea of accessibility.

163. Strack \& Mussweiler, supra note 39, at 80. See also Guthrie \& Rachlinski, supra note 40, at 2027 ("Regardless of the underlying explanation, anchoring is a powerful phenomenon.").

164. Orr \& Guthrie, supra note 36 , at 600 . Legal bargaining theorists also use the experiment as evidence of the power of anchoring. Id.; Guthrie \& Rachlinski, supra note 40, at 2026; Richard Birke \& Craig R. Fox, Psychological Principles in Negotiating Civil Settlements, 4 HarV. Negot. L. REV. 1,10 (1999).

250 
[Vol. 10: 2, 2010]

1970s. ${ }^{165}$ The experiment was as simple as it was ingenious. Kahneman and Tversky divided their subjects into a number of groups and asked each subject to estimate the percentage of African countries in the United Nations. ${ }^{166}$ Before permitting them to do this, however, the researchers spun a "wheel of fortune" in the subjects' presence, rigged to stop at different numbers for different groups. ${ }^{167}$ The subjects then were asked to say whether the percentage of African countries was higher or lower than their respective wheel numbers, and to estimate the actual percentage by moving up or down from the numbers. ${ }^{168}$ Each group of subjects produced a different median estimate. In the two examples reported by Kahneman and Tversky, the median guess of those in a group shown the wheel number of ten was twenty-five percent, and the median guess of those in a group shown the wheel number of sixty-five was forty-five percent. ${ }^{169}$ An irrelevant number, generated by the spin of a wheel, seemed to have influenced the subjects' decisions and this, Kahneman and Tversky concluded, was irrational. ${ }^{170}$

165. Tversky \& Kahneman, supra note 48, at 1128. Strack and Mussweiler call it "one of the most dramatic demonstrations" of the power of anchoring available. Strack \& Mussweiler, supra note 39 , at 80 .

166. In the complete experiment subjects were asked to estimate a number of different things, the percentage of African countries in the United Nations was only one of them. Tversky \& Kahneman, supra note 48, at 1128.

167. Id.

168. Id.

169. This was a so-called between-subjects experiment, in that it compared the median response of one group of subjects to the median response of another group. Its corollary, the so-called withinsubjects experiment, would compare the responses of individual subjects within a group, tested under different conditions, with one another. Each type of experiment has strengths and weaknesses and there is a difference of opinion over which design provides more trustworthy insights. Compare Mitchell, Taking Behavioralism Too Seriously?, supra note 24, at 1946-54 (discussing the comparative strengths and weaknesses of between-subjects and within-subjects experiments) with Prentice, Chicago Man, supra note 24, at 1679-86 (discussing the comparative strengths and weaknesses of between-subjects and within-subjects experiments).

170. Tversky \& Kahneman, supra note 48, at 1128 ("arbitrary numbers had a marked effect on estimates"). "Irrational" in this context means based on an error, rather than completely devoid of reason. See Mitchell, Taking Behavioralism Too Seriously?, supra note 24, at 1972 ("Kahneman and Tversky, like many other behavioral decision theorists, sought to elicit errors to illuminate underlying psychological processes rather than determine the prevalence of irrational behavior."). See also Mitchell, Why Law and Economics, supra note 33, at 81 (The "application of... [procedural rationality] principles does not necessarily lead to the most adaptive or best solution to any given decision problem."). 
Social scientists have conducted numerous anchoring experiments since Kahneman and Tversky's pioneering effort, ${ }^{171}$ testing the effect of different sorts of anchors on a wide variety of predictive and probabilistic judgments about quantity and value, and most of these experiments have reached the same or a similar conclusion. ${ }^{172}$ Anchoring, according to this research, is a pervasive feature of human decision making, a basic characteristic of "rational" life. ${ }^{173}$ While its contributions to ordinary judgment can be mixed, sometimes providing helpful shortcuts and sometimes misleading distortions, within legal dispute settlement anchoring's effects are potentially pernicious because they can cause judges and lawyers to resolve legal claims on the basis of factors that have little or no relationship to the claims' substantive merits. ${ }^{174}$ Moreover, bargainers who are aware of the anchoring heuristic, say legal bargaining theorists, are able to exploit it to obtain better than average results, even when they "cannot possible justify" them, ${ }^{175}$ and this also is a cause for concern. Whether these are serious concerns is the question to which we now turn.

\section{ANCHORING RESEARCH AND LEGAL BARGAINING}

Anchoring's influence on decision making generally is for others to describe. The important issue for present purposes is what type of influence, if any, it exerts over the practice of settling legal disputes. Is it a magic bullet for manipulating adversaries? A low-level distraction easily neutralized by understanding and skill? A structural determinant of outcome? Or what? Just how concerned should legal bargainers be about

171. Orr \& Guthrie, supra note 36, at 615-17 tbl.3 (listing the various studies included in metaanalysis of anchoring studies). See also Prentice, Chicago Man, supra note 24, at 1678, 1695 ("The rich literature of heuristics and biases ... includes thousands of studies seeking to confirm, rebut, and/or [sic] determine the limits and conditions of the K-T findings.") ("Many of the important heuristics and biases in the Kahneman and Tversky tradition have been demonstrated in literally hundreds of published studies.").

172. Orr \& Guthrie, supra note 36, at 621-28 (describing the results of various studies testing the impact of an opening number on negotiation outcome).

173. Id.

174. Id. at 608-10. In two well known experiments involving personal injury claims, for example, subjects awarded less money to plaintiffs whose insurance policy limits were lower than those of other plaintiffs with identical claims. See id. at 609-11 (citing Jeffrey J. Rachlinski \& Chris Guthrie, Litigation Stakeholders: Repeat Player Resistance to Cognitive Bias (Feb. 17, 2006) (working paper on file with author). Another set of subjects settled identical claims for defective goods for smaller amounts with parties who made low opening demands than with parties who made high opening demands. See Russell Korobkin \& Chris Guthrie, Opening Offers and Out-of-Court Settlement: A Little Moderation May Not Go a Long Way, 10 OHIO St. J. ON DisP. Resol. 1, 19 (1994).

175. Orr \& Guthrie, supra note 36 , at 625. 
[Vol. 10: 2, 2010]

PEPPERDINE DISPUTE RESOLUTION LAW JOURNAL

the sub rosa influence of anchors? These and other such questions will occupy us in the sections that follow.

\section{A. Anchoring Often Is Rational}

Legal bargaining scholars offer the African Countries experiment as evidence that individuals can be induced to make bargaining judgments irrationally, ${ }^{176}$ on the basis of irrelevant anchor information. However, there may be more going on in that experiment than meets the eye. Consider the situation facing the subjects. If someone did not know the percentage of African countries in the United Nations (and who, except for the occasional game-show wannabe, would?), ${ }^{177}$ he would have to guess. Guessing, by definition, does not involve a rational calculation (though the decision to guess might). Reason might limit the range of acceptable guesses (no one would guess one hundred percent, for example, or zero percent), but it does not identify the best guess within that range, and the range could be very large.

176. See Tversky \& Kahneman, supra note 48, at 1128.

177. Questions in anchoring experiments usually ask about game-show type information that most people would not be expected to know (e.g., the length of the Mississippi River, the frequency of fraud in large corporations, the average temperatures in San Francisco, the relationship of the width of the Brandenburg Gate to its height, the number of top-ten Beatles' records, and the like). See Reid Hastie, A Review from a High Place: The Field of Judgment and Decision Making as Revealed in its Current Textbooks, 2 PSYCHOL. SCI. 135, 138 (1991) (describing behavioral decision theory experiments as often based on "60-second brainteaser problems"). Subjects might view questions of this sort as "extra-rational" and dismiss them as not serious. This, in turn, could authorize a kind of "extra-rational" behavior in response. Cf. Mitchell, Taking Behavioralism Too Seriously?, supra note 24, at 1979 (

A great deal of research in the last ten years has shown that subjects often provide nonnormative responses in behavioral decision-making experiments not because the subjects are incapable of acting rationally but because the experimental situation indicates, or communicates, that the non-normative response is the correct or desired answer under the circumstances.).

Mitchell illustrates the point using the Guthrie et al. study of federal judges as an example. Id. at 1996-2002 (citing Guthrie et al., supra note 110, at 778.). He argues that it is not possible to conclude that the judges committed reasoning errors in filling out their questionnaires without knowing the judges' objectives. Id. at 1999 ("Indeed, if a judge's goal was simply to complete the questionnaire as quickly as possible, then randomly answering the questions may have been the most efficient route to achieving this goal."); see also Prentice, Chicago Man, supra note 24, at 1713 ("Mitchell's attack ... is that ... the judges' main goal was simply to complete the questionnaire as quickly as possible so that they could get out to the golf course."). 
A guess is an opinion not supported by evidence or reasoning. ${ }^{178}$ Guessing is like playing the lottery. Any answer could be correct but there is no way of knowing in advance whether it will be. Under these conditions, almost any method for choosing an answer is as sensible (i.e., rational) as almost any other method. ${ }^{179}$ Identifying the percentage of African countries based on the spin of a wheel is a little like picking a lottery number based on a birth date (wedding anniversary, license plate, day of the week, or whatever). It has as much or as little chance of succeeding as any other method in a situation in which no option has any better chance of success. ${ }^{180}$ This does not make choosing on the basis of the spin of a wheel rational, but neither does it make it irrational. ${ }^{181}$ It is simply an operational example of the familiar decisional aphorism of "any port in a storm."

Determining how to interpret the African Countries experiment is complicated further by the fact that the subjects in the experiment simply may have been following an order to anchor. ${ }^{182}$ In the experiment, they were

178. See Merriam Webster's Collegiate Dictionary 555 (11th ed. 2007) (“Guess . . . to form an opinion of from little or no evidence").

179. Setting a reservation price in bargaining presents a similar situation. See Korobkin, supra note 37 , at 38 (

[T] he factors that logically should inform the plaintiff's reservation price are often difficult to assess and fraught with uncertainty, making the normative determination of a reservation price in accordance with the standard [economic] model difficult. Given this practical difficulty, a plaintiff might base her reservation price, at least in part, on information that is not logically relevant from a normative perspective.).

The experiment rewarded only correct answers, not answers that were close to being correct. The absence of multiple choice questions also prevented subjects from increasing their chances of being correct by eliminating less probable answers first. Residual SAT test-taking skills thus were of no value in the experiment.

180. The justification for extraterritorial service of process (also referred to as "substitute" or "publication" service) on unknown or missing beneficiaries in a trust accounting is based on a similar idea. See Mullane v. Cent. Hanover Bank \& Trust Co., 339 U.S. 306, 317 (1950).

This Court has not hesitated to approve of resort to publication as a customary substitute [for personal service] in another class of cases where it is not reasonably possible or practicable to give more adequate warning. Thus it has been recognized that, in the case of persons missing or unknown, employment of an indirect and even a probably futile means of notification is all that the situation permits and creates no constitutional bar to a final decree foreclosing their rights.

Id. There is no reason to believe such service will work, but there also is no reason to believe that it is any less likely to work than other available options. $I d$.

181. See Jolls \& Sunstein, supra note 48, at 204 ("Bounded rationality is hardly the same as irrationality.") (citation omitted). Alex Stein argues that there is no reason to treat "the narrow paradigm of [economic] rationality ... as a baseline for assessing people's performance.... Why not adopt ... the inclusive liberal position that perceives rationality as a complex and multifaceted phenomenon?" Stein, A Liberal Challenge, supra note 89, at 534. "There are many different rationalities," rather than just one, "and [Prospect Theory's] experimental designs need to take this pluralism into account." Id. at 540 .

182. See Tversky \& Kahneman, supra note 48 , at 1128 . 
[Vol. 10: 2, 2010]

PEPPERDINE DISPUTE RESOLUTION LAW JOURNAL

told to make the wheel number the baseline from which to calculate their final estimates. ${ }^{183}$ In going along with this instruction they may have been trying to be dutiful research subjects. Seen in this way, their estimates would be the result of a quasi-Milgram effect, ${ }^{184}$ a nonviolent variation of

183. Id. at 1128. But see Strack \& Mussweiler, supra note 39, at 81 (arguing that because the anchor number was "randomly generated by a spinning wheel of fortune in front of the participants' eyes," it is difficult to explain its influence as a consequence of the participants trusting a "conversational inference" made from the researchers' instructions).

184. "Milgram effect" takes its name from a series of social-psychology experiments conducted at Yale in the 1960s, designed to measure the willingness of people to obey authority figures even when instructed to perform acts that conflicted with personal conscience. See Stanley Milgram, Behavioral Study of Obedience, 67 J. ABNORMAL \& SOC. PsYchol. 371 (1963). In the actual Milgram Experiments subjects were instructed to administer electric shocks to "learners" who made mistakes answering questions. Id. The experiments are named for Stanley Milgram, a Yale social psychologist who ran the first iteration in 1961. See id. See also Stanley Milgram, Obedience TO AUthority: AN EXPERIMENTAL VIEW (1974). Milgram described the lessons learned from the experiments in this way:

The legal and philosophic aspects of obedience are of enormous import, but they say very little about how most people behave in concrete situations. I set up a simple experiment at Yale University to test how much pain an ordinary citizen would inflict on another person simply because he was ordered to by an experimental scientist. Stark authority was pitted against the subjects' strongest moral imperatives against hurting others, and, with the subjects' ears ringing with the screams of the victims, authority won more often than not. The extreme willingness of adults to go to almost any lengths on the command of an authority constitutes the chief finding of the study and the fact most urgently demanding explanation.

Stanley Milgram, The Perils of Obedience, HARPERS, Dec. 1973, at 62. Like other mid-twentieth century projects of a similar nature the experiments were prompted, in part, by the rise of authoritarian political regimes across the world and the desire to understand what could cause citizens to support them. The experiments were preceded by the so-called Asch Conformity Experiments conducted by the American Gestalt psychologist Solomon Asch in the early 1950s, and were followed by the infamous Stanford Prison Experiment conducted by Philip Zimbardo (a high school classmate of Milgram's) in the 1970s. See Solomon E. Asch, Opinions and Social Pressure, 193 SCI. AM. 31 (1955); Craig Haney, Curtis Banks \& Philip Zimbardo, Interpersonal Dynamics in a Simulated Prison, 1 InT'L J. CRIMINOlogy \& Penology 69 (1973). The Stanford Prison Experiment has an official website. See Stanford Prison Experiment, http://www.prisonexp.org/ (last visited Nov. 14, 2009). For a description of a 2006 facsimile of the Milgram experiments performed at Santa Clara University, see Jerry M. Burger, Replicating Milgram: Would People Still Obey Today?, 64 Am. PsychOLOGIST 1 (2009). Professor Mitchell describes other ways in which "social factors or sources of uncertainty may dramatically affect the subject's construal of the task." Mitchell, Why Law and Economics, supra note 33, at 108; Mitchell, Taking Behavioralism Too Seriously?, supra note 24, at 1981-82 (describing how research participants assume that utterances of researchers are meaningful and try to make sense of and abide by them) (citing Norbert Schwarz, Judgment in a Social Context: Biases, Shortcomings, and the Logic of Conversation, 26 ADVANCED EXPERIMENTAL SOC. PSYCHOL. 123, 154-56 (1994)). But see Prentice, Chicago Man, supra note 24, at 1707 (describing how "[r]esearchers are well aware of the impact of ... [subjects] try[ing] to please the experimenter"). 
the tendency to obey the instructions of research directors in social science experiments, even when it makes no sense to do so. ${ }^{185}$ Research subjects do all kinds of strange things when told to, but that does not mean that they will take the same direction from adversaries in real life bargaining. ${ }^{186}$ In fact, one of Prospect Theory's principal biases suggests quite distinctly that they will not. ${ }^{187}$ The so-called reactive devaluation bias holds that bargainers view proposals from adversaries as "less desirable than [they] otherwise would merely because [an adversary] has offered [them]."188 Reactive devaluation and anchoring seem to work at cross purposes in bargaining, ${ }^{189}$ therefore, cancelling one another out as if "paired in the voting." 190

There is an additional complication. Kahneman and Tversky gave each group of subjects a different wheel number, but the relationship of each wheel number to its respective group median percentage estimate was not the same. ${ }^{191}$ The wheel number of ten, for example, was closer to the corresponding group estimate of twenty-five percent than the wheel number

185. See Burger, supra note 184. This tendency often is unknowing and harmless. Alex Stein describes a similar situation in his discussion of the Blue Cab experiment. See Stein, supra note 89, at 538. Subjects in the experiment

knew nothing about the correlation... between cab distribution in the city and the accuracy of cab-identifying witnesses. They therefore had an epistemological warrant to believe the witness by assessing the accuracy of his cab identification as $80 \%$ probable [as the experimenter had told them]. This assessment was as rational as one that does take the cab distribution into account. The choice between the two approaches depends on how one wants to allocate the risk of error; there is more than one rational way of Id. doing it.

186. See, e.g., Dan Coates \& Steven Penrod, Social Psychology and the Emergence of Disputes, 15 LAW \& SOC'Y REV. 655, 667 (1980-1981) ("It is often difficult to generalize from results obtained under such [experimental] conditions to more realistic injurious experiences and disputes.").

187. Korobkin \& Guthrie, supra note 40, at 804-05.

188. Lee Ross \& Constance Stillinger, Barriers to Conflict Resolution, 7 NeGOT. J. 389, 392 (1991) (describing reactive devaluation); see Korobkin \& Guthrie, Heuristics and Biases, supra note 40, at 804-05 (describing reactive devaluation); Korobkin \& Guthrie, Psychological Barriers, supra note 37 , at 150-60 (describing reactive devaluation).

189. See Korobkin \& Guthrie, supra note 40, at 805 (The reactive devaluation heuristic can "cause a negotiator to reject a proposed agreement... when she would have made precisely the opposite choice had the same proposal emanated from another source.").

190. In this respect, Prospect Theory biases may be similar to the canons of statutory construction. In Karl Llewellyn's well known terminology, for example, every "Thrust" may have a countervailing and neutralizing "Parry." See Karl N. Llewellyn, Remarks on the Theory of Appellate Decision and the Rules or Canons About How Statutes Are to Be Construed, 3 VAND. L. REV. 395 , 401-06 (1950) (arguing that "there are two opposing canons on almost every point" and appending a list of "Parry" and "Thrust" canons). But see ANTONIN SCALIA, A MATTER OF INTERPRETATION: FEDERAL COURTS AND THE LAW 27 (1997) ("Llewellyn's 'Parries' do not contradict the corresponding canon but rather merely show that it is not absolute.").

191. See Tversky \& Kahneman, supra note 48, at 1128. 
[Vol. 10: 2, 2010]

PEPPERDINE DISPUTE RESOLUTION LAW JOURNAL

of sixty-five was to the corresponding group estimate of forty-five percent; and one group estimate was higher than the wheel number, while the other was lower. ${ }^{192}$ If Prospect Theory is correct about the influence of anchor numbers, these differences seem a little surprising. If the wheel numbers acted as anchors one would have expected them to exert their influence in roughly the same way in each circumstance, but that did not happen. Subjects in each group seemed to reason first and then to guess, but each in a different way. The subjects in the forty-five percent group appear not to have allowed the wheel number of sixty-five to inflate their estimates beyond what seemed reasonable, just as the subjects in the twenty-five percent group appear not to have allowed the wheel number of ten to deflate their estimates below what seemed reasonable. Subjects in the sixty-five group calculated down from the wheel number ${ }^{193}$ and subjects in the ten group calculated up, suggesting that all of the subjects made rough reasonableness calculations before using the wheel numbers to shape their guesses. ${ }^{194}$ In a world with no better option, this seems a perfectly sensible thing to do. ${ }^{195}$

\section{B. Anchor Numbers Usually Do Not Have Independent Influence}

Anchor numbers do not exist as free-standing entities, shaping settlement agreements all by themselves. All moderately complex legal bargaining contains a cacophony of numbers, both spontaneous and planned, embedded in the proposals, offers, arguments, and off-the-top-of-the-head comments of the parties and their lawyers. Some of these numbers will turn out to be similar, or even identical, to final settlement terms and some will

192. Id.

193. This might not be true for each member of the subject group. Kahneman and Tversky report median estimates, not individual answers. See id.

194. Some Prospect Theory experiments ask subjects to generate their own anchors. See, e.g., Nicholas Epley \& Thomas Gilovich, Putting Adjustment Back in the Anchoring and Adjustment Heuristic, in HEURISTICS AND BIASES, supra note 39, at 139, 142-45 (when asked to estimate the freezing point of vodka, researchers found that subjects anchored on thirty-two degrees Fahrenheit on their own, without having it suggested to them, and adjusted down from that number). Interestingly, the subjects' reasoning in the African Countries experiment is similar to the reasoning process underlying common law decision making. Courts decide cases on the basis of prior cases viewed as similar; cases need not be identical to be precedent. It would be ironic if anchoring was an inappropriate basis for informal dispute settlement at the same time it was a linchpin of formal dispute settlement.

195. Tversky \& Kahneman, Judgment, supra note 48, at 1125 (describing how subjects in another experiment "used prior probabilities correctly when they had no other information"). 
not, but all of them will depend for their influence - their anchoring effect if you will - not on what they say but on how they are defended and justified. It is the advocacy and leveraging moves made in support of anchor numbers, and not the numbers themselves, that give the numbers their force. In a sense, anchor numbers are an outcome of a negotiation as much as they are a cause of a negotiation outcome. Or, perhaps more accurately, they are an outcome of the advocacy and trading contests between opposing bargainers that constitute negotiation.

The best way to understand how anchor numbers blend with party maneuvers, situational forces, and structural factors to shape final agreement is to examine the process in operation in an actual negotiation. I describe such a negotiation in the article Bargaining With a Hugger. ${ }^{196}$ While working in Charlottesville, Virginia, for the hypothetical Drill Company (Drillco), Phillip Paine was offered a one-year assignment at the company's Venezuelan refinery. He was told that while on assignment he would be given fixed-foundation housing and would be permitted to return to the United States to deal with emergencies. When he arrived in Venezuela, however, he was offered mobile home housing and when he returned to the United States to resolve a problem with his mortgage he was fired for "leaving Venezuela without permission.", American employee on the Venezuelan assignment and the only employee treated in this way. ${ }^{198}$ He filed suit against Drillco in federal district court, alleging that he was discharged on the basis of race, in violation of 42 U.S.C. $\S 1981$ and 42 U.S.C. $\S 2000$ e $^{199}$ The case was referred to a magistrate for discovery and motion practice, and the magistrate scheduled a Rule 16 pre-trial conference to discuss settlement. ${ }^{200}$

The conference began with a full group meeting of the magistrate and lawyers, but when discussion turned acrimonious the magistrate adjourned the meeting to caucus privately with each side. The magistrate met with the

196. Condlin, supra note 92, at 16-69.

197. Id. at 18 .

198. Id. at 17-18.

199. Drillco was represented by a senior Title VII partner from one of the country's largest law firms and Paine was represented by two private attorneys, each of whom had extensive and highlevel Title VII litigation experience. $I d$. at 16. The conference was videotaped and transcribed. Id. The lawsuit was hypothetical, though it was based on an actual suit filed in New Jersey federal district court. Id. at 18. The original action had been settled but the participants in the Drillco conference did not know the terms of the settlement. Id. Each participant was given a complete case file (i.e., pleadings, motions, rulings, deposition transcripts, correspondence, evidentiary documents, pictures, physical evidence, research memoranda and witness profiles, all modified to make the parties anonymous) and asked to reach an agreement with the other side only if possible. Id. The conference lasted for almost three hours. Id. at 19 n.54.

200. Id. at 18-19. 
[Vol. 10: 2, 2010]

Drillco lawyer first and without much difficulty convinced him to offer Paine twenty thousand dollars to settle the case. When he took this offer to Paine's lawyers, however, they demanded that Paine be reinstated to his previous job and be given one hundred thousand dollars for lost back pay. If Drillco did not agree to these terms, the lawyers wanted two hundred thousand dollars to compensate Paine for his lost front and back pay combined. These demands were new. They had not been pleaded, included in the pre-trial order, or mentioned in the full group meeting. The magistrate argued with the lawyers, sometimes heatedly, for about forty-five minutes, until each side agreed to a compromise offer of reinstatement plus thirty thousand dollars. The magistrate presented the compromise to the Drillco lawyer who, after some extended foot-dragging and with considerable reluctance, accepted it. This was an exceedingly pro-Paine settlement. ${ }^{201}$ With the elimination of front pay damages through reinstatement, Paine received more than ninety percent of what he could have hoped to win at trial. By the time the conference was over the Paine lawyers had changed the magistrate's assessment of the case, the magistrate had changed the Drillco lawyer's assessment, and Paine had done very well.

Because Paine's opening demand was large (two hundred thousand dollars without reinstatement or one hundred thousand dollars with), and because the final agreement was favorable to Paine, one is tempted to see the demand as anchoring the outcome in Paine's favor, ${ }^{202}$ but that would be a mistake. In and of itself, Paine's opening demand was laughable - in fact, that was the magistrate's first reaction ${ }^{203}$ - and the parties might have rejected it out of hand but for subsequent events. Only when combined with several other contingent factors did the demand play a role in shaping the final agreement. When asked to justify the two hundred thousand dollars in lost front pay (if reinstatement was denied), Paine's lawyers analogized Paine's case to an age discrimination claim (where front pay calculations are more common because plaintiffs often do not find new work), and argued that the formula used in age cases should be used to calculate front pay damages for Paine. This argument seemed to catch the magistrate by surprise and short-circuit his efforts to challenge the two hundred thousand dollar figure. Age discrimination was not an issue in Paine's case and the

\footnotetext{
201. Id. at 19-20.

202. See id. at 20. This is particularly true when one compares the excessiveness of the Paine lawyers' opening demand to the reasonableness of the Drillco lawyer's counter-offer.

203. He dismissed the "one hundred thousand dollars plus reinstatement" demand with a perfunctory "No way." Id. at 37 n.116.
} 259 
magistrate, understandably, was not prepared to discuss it. ${ }^{204}$ As a consequence, he gave the argument more credence (or challenged it less vigorously) than he otherwise might have and this, in turn, caused him to look less skeptically at the two hundred thousand dollar demand. ${ }^{205}$ Having accepted the age discrimination argument, or not having rebutted it, the magistrate then used it to press the Drillco lawyer to agree to Paine's counter-offer. The Drillco lawyer was equally unprepared to argue age discrimination and agreed to everything the magistrate asked for.

Other non-demand factors also contributed to the outcome. The magistrate was worried that Paine's lawyers would amend their complaint to add a disparate impact claim and that this would open up the possibility of "cash register" damages at trial. ${ }^{206}$ The lawyers had not threatened to do this and, in fact, had not contemplated it, but for some reason (at the time unexplained), ${ }^{207}$ the magistrate was convinced that the risk was real. The lawyers had made the two hundred thousand dollar demand largely for its in terrorem effect and as an escalation move to make their one hundred thousand dollar demand look attractive by comparison, ${ }^{208}$ but in doing so, they unknowingly had exploited a private fear of the magistrate. It was the triggering of this private fear, not the two hundred thousand dollar figure itself, that gave the demand its force. ${ }^{209}$ Like the age discrimination Id.

204. See id. at 40. Paine was in his thirties and had not pleaded an age discrimination claim.

205. The age discrimination argument might have held up under scrutiny, though Paine's lawyers did not think it would. See id. at 39 . But without ever being fully tested, it was given the kind of deference traditionally reserved for demonstrably correct arguments. Ideally, one would not concede to an argument that had not been defended convincingly, but it is not possible to anticipate every argument another bargainer might make, hard to admit that an argument comes as a surprise, and bad form to take a break to do more preparation. Sometimes one must go forward on wits, intuition, general knowledge, and gut reaction, and unfamiliar arguments can be powerful in such circumstances, even when wrong. See Gary Goodpaster, Negotiation and Mediation: A Guide to NeGotiation AND NEgotiated Dispute Resolution 123-35 (1997) (describing the non-rational aspects of negotiator decision-making); Birke \& Fox, supra note 164, at 24, 36-37 (describing the non-rational aspects of negotiator decision-making); Korobkin \& Ulen, supra note 36, at 1084-1109 (describing the non-rational aspects of negotiator decision-making).

206. Condlin, supra note 92 , at 31 .

207. Id. at 32. The magistrate revealed later that he had presided over another pre-trial conference in which that had happened. $I d$.

208. The one hundred thousand dollar demand might have had more influence given its greater realism, but the request for reinstatement was probably the lawyers' most successful move. Id. By eliminating the risk of lost front pay, reinstatement eliminated the largest part of Paine's damages and pretty much guaranteed that he would come out ahead. Id. Often, in the heat of negotiation, it is difficult to appreciate the full significance of a demand that is expressed in non-monetary terms, however, and the magistrate and Drillco lawyer had that difficulty here.

209. Id. at 38. The lesson in Paine's lawyers' success is: "defend an aggressive first offer in a clever and powerful way," more than it is: "make an aggressive first offer."

260 
[Vol. 10: 2, 2010]

PEPPERDINE DISPUTE RESOLUTION LAW JOURNAL

argument, the tacit threat of a disparate impact claim was a contingent and fortuitous event in the negotiation that easily might not have occurred. The two taken together, in combination with other such events, ${ }^{210}$ worked their influence collectively, as parts of a package of complementary and mutually reinforcing moves, and not as independent entities, to pressure the magistrate to accept Paine's demands. Agreement resulted from the confluence of many forces, in other words, not a single anchoring maneuver, and some version of this scenario is present in almost all legal bargaining.

\section{Anchors Can Be Avoided or Overcome}

Anchors exert less influence in "information-rich environments" 211 and among "expert" negotiators ${ }^{212}$ than they do with novices, but even novices can avoid or minimize their "pernicious effects" by adopting "de-biasing" strategies. ${ }^{213}$ Debiasing strategies come in two principal types, inside and

210. The magistrate's decision to meet with the Drillco lawyer first guaranteed that Drillco would make the first offer. Id. at 45 . The Drillco lawyer could not bring himself to make an inflated offer, given his longstanding relationship with the magistrate, so he made a reasonable one. Id. at 51. Paine's lawyers did not know the magistrate and did not feel a similar compunction to be reasonable, so they countered with a greatly inflated offer. $I d$. at 52 . This left the bargaining range imbalanced in Paine's favor and pretty much guaranteed that he would get the better result. Id. Contingent factors of this sort are present in all negotiation and bargaining skillfully consists, in part, of being able to identify and exploit them.

211. In bargaining, an "information rich-environment" is one in which the parties have accurate information about another's costs, reservation prices, aspiration levels, and practical constraints.

212. Orr and Guthrie seem to use "expert" as a synonym for "experienced." Orr \& Guthrie, supra note 36, at 598. For example, they describe their study as measuring the extent to which "information and expertise" limit the impact of anchoring, but then discuss "expertise" exclusively in terms of bargainer experience. Id. at 623. See also Kahneman, Maps, supra note 33, at 1457 ("Experienced traders ... learned to base their choice on long-term value, rather than on the immediate emotions associated with getting or giving up objects."). Plea bargaining between criminal defense lawyers and prosecutors illustrates the way in which experience can temper the influence of heuristics and biases. As Professor Oldfather explains, "“[w]ere one to form predictions about plea bargaining based only on cognitive research, it would be logical to expect plea bargaining to be a rare occurrence,' ... [yet] over ninety percent of all criminal cases are resolved by plea bargain." Oldfather, supra note 38, at 252 (citation omitted) (alteration in original). This is because criminal defendants and their lawyers are more experienced at making plea bargaining decisions than humans are at making decisions generally.

213. Orr \& Guthrie, supra note 36, at 625 ; see Trout, supra note 48 , at 417 ("“The] lessons of the empirical work on judgment and choice... do not show that people CAN'T make good choices ... [r]ather, the psychological findings show that people ... DON'T make good choices."); see also Weinstein, supra note 31, at 792-93, n.27 ("Empirical work suggests that we can improve our judgment if we are conscious of our cognitive biases and practice correcting them ... [though] it 261 
outside. "An inside strategy is a voluntary reasoning process designed to improve [the] accuracy of judgment[s] by creating a fertile corrective environment in the mind." ${ }^{214}$ The most effective inside strategy "calls [on a] negotiator to consider the opposite perspective before deciding whether to accept an [adversary's] offer.",215 In "considering the opposite," a bargainer evaluates an offer from both his own perspective and that of his adversary, ${ }^{216}$ focusing on arguments for and against the offer rather than the offer's numeric content. This, say legal bargaining theorists, can prevent the offer from becoming an anchor. ${ }^{217}$ There is little to disagree with in this advice, of course, though there is some question of whether it needs to be said. The importance of understanding issues from multiple (including adverse) perspectives is the central message of legal education, and given its familiarity, being reminded of it is likely to leave most lawyers waiting for the rest of the story. Fortunately, there is no need to wait, since inside

can be difficult for even trained, careful professionals to identify and completely correct for the way our minds work.").

214. Trout, supra note 48, at 418 (emphases omitted); Daniel Kahneman \& Dan Lovallo, Timid Choices and Bold Forecasts: A Cognitive Perspective on Risk Taking, 39 MGMT. 17, 24-27 (1993) (describing "inside" and "outside" perspectives on forecasting problems).

215. Orr \& Guthrie, supra note 36 , at 626 ; Trout, supra note 48 , at 418 ("[T] he 'consider the opposite' strategy ... urges people to consider alternative hypotheses for the occurrence of the very event that they believe they understand."); Mitchell, Why Law and Economics, supra note 33, at 133-34 n.207 (reporting on studies showing that asking subjects to consider opposing arguments helps ameliorate the adverse effects of several biases, including anchoring). Debiasing can begin even before meeting with another bargainer. Wilson and his colleagues describe how one "about to hear a speech from an untrustworthy source... can try to strengthen her mental defenses by engaging in anticipatory counterarguing." Timothy D. Wilson, David B. Centerbar \& Nancy Brekke, Mental Contamination and the Debiasing Problem, in HeURISTICS AND BIASES, supra note 39, at 185, 193. They describe this strategy, somewhat prosaically, as "preparation." Id. at 192. Strategies undertaken before bias-inducing information is received can be the most effective, but also the most risky, because they can lead to an overabundance of caution and prevent a bargainer from learning useful information. Id. at 195.

216. Malhotra \& Bazerman, supra note 32, at 524 (describing different ways of "slowing down the pace of the interaction and evaluating the appropriate response [to the adversary's position] more deliberately").

217. Orr \& Guthrie, supra note 36, at 626; Trout, supra note 48, at 419 (describing the "fairly demanding set of conditions" necessary for inside debiasing strategies to be effective). Bargainers can avoid the effects of anchoring even in laboratory experiments. Gilbert illustrates how this is done with a study of subjects watching a video of a woman responding to questions. Gilbert, supra note 39 , at 170 . The subjects could not hear the woman's answers but they were given descriptions of the topics being discussed at the bottom of the screen. $I d$. The subjects were divided into two groups, with one group shown uncomfortable topics and the other shown emotionally neutral ones. Id. The woman was visibly upset throughout the questioning and subjects were asked whether they thought this meant she was an anxious person generally. Id. Despite anchoring on the woman's nervousness, subjects who thought the questions were uncomfortable adjusted their thinking to conclude that her discomfort was produced by the questions and not her disposition, while subjects who thought the questions were neutral reached the opposite conclusion. Id.

262 
[Vol. 10: 2, 2010]

PEPPERDINE DISPUTE RESOLUTION LAW JOURNAL

strategies "provide only limited protection" against anchoring. ${ }^{218}$ Outside strategies are the ones more likely to work. ${ }^{219}$

An outside strategy "identifies features of the environment whose presence can be manipulated to produce the most accurate or desirable available outcome." 220 Outside strategies are structural, not personal, changing the nature of the "problem dynamic entirely," not just the bargainer's internal state of mind. ${ }^{221}$ Strangely, because it looks more like an inside strategy than an outside one, Orr and Guthrie describe the adoption of an "outside view" of the bargaining problem as a prototypical outside strategy. ${ }^{222}$ An "outside view" ignores the details of the case at hand and "focuses [instead] on the statistics of a class of cases chosen to be similar in relevant respects to the present one."223 Consulting "Consumer Report [sic] or Kelley's Blue Book" [sic] to determine what to pay for an automobile, rather than "relying solely on the initial demand made by the car dealer," 224 or consulting "settlement and verdict data from comparable cases" to determine the value of a personal injury claim, rather than relying on an

218. Orr \& Guthrie, supra note 36 , at 626.

219. Trout, supra note 48 , at 420 (" $[\mathrm{T}]$ he more effective debiasing strategies... are predominantly outside strategies.").

220. Orr \& Guthrie, supra note 36, at 626 (quoting Trout, supra note 48, at 420).

221. Id. at 625-26. Trout uses a "term limits" example to illustrate the concept of an outside strategy.

[I]ndependent auditors [can be prohibited] from working with a bank or brokerage firm for more than, say, five consecutive years. Rather than simply advising auditors to be impartial, or expecting them to be professional and direct in delivering bad news to the company responsible for their employer's financial growth, th[is] outside strategy removes the threat to integrity by eliminating its source.

Trout, supra note 48 , at 421 .

222. The "outside/inside" distinction can be confusing. Because the adoption of an "outside view" occurs "inside" the negotiator's head, it is not clear whether, or why, it is an outside strategy. See, e.g., Orr \& Guthrie, supra note 36, at 625 ("Inside strategies are those within the negotiator's mind."). An outside strategy expands the individual bargainer's personal perspective on the problem more than it alters the incentive and constraint structure within which the bargainer operates. That notwithstanding, I will use Orr and Guthrie's terminology.

223. Id. at 626 (quoting Kahneman \& Lovallo, supra note 214, at 25).

224. Id. at 626-27. As sensible as this advice seems, many people do not seem to be aware of it. See Ian Ayres, Fair Driving: Gender and Race Discrimination in Retail Car Negotiations, 104 HARV. L. REV. 817, 856 (1991) ("The Consumer Federation of America recently completed a survey which revealed that thirty-seven percent of consumers do not understand that the sticker price is negotiable."). "Similarly, during interviews conducted in confidential litigation research... prospective jurors were asked whether 'most people pay sticker price for their cars.' Twenty percent of those surveyed responded 'yes." Id. at $856 \mathrm{n} .115$. 
adversary's demand, are examples of adopting an outside view. ${ }^{225}$ Consulting industry standards and comparable case data makes sense, of course. It is a variation of the strategy, popularized by Principled Bargaining Theory, of using "objective criteria" to determine the value of an offer. $^{226}$ But it is not clear what the concept of de-biasing adds to the concept of objective criteria or, given the latter, why it is needed. This may be another instance of "nominalism about realism" being offered up as new theory. 227

\section{Anchoring Is Not News}

Perhaps the most prominent characteristic of the effort to adapt the insights of anchoring research to legal bargaining theory is the obviousness

225. Orr \& Guthrie, supra note 36, at 626-27. The ultimate "outside strategy" for someone who "need[s] negotiation services [is] to hire [a] lawyer." $I d$. at 627 . This is because "experts are somewhat less susceptible to the effects of anchoring, and lawyers are the consummate expert negotiators.... [They are] more 'rational' and analytical than many other members of the population ... [and] better able ... to resist biases." Id. at 627-28. See also Korobkin \& Guthrie, supra note 113, at 99-100, 105-06 (reporting evidence that shows lawyers appear to be less susceptible to heuristics and biases when advising clients about settlement options).

226. See FISHER, URY \& PATTON, supra note 85, at 84-93 (describing the process of insisting on "objective criteria"). Kahneman also describes the importance of using what he describes as "canonical" criteria. Kahneman, Maps, supra note 33, at 1459.

Absent a system that reliably generates appropriate canonical representations, intuitive decisions will be shaped by the factors that determine the accessibility of different features of the situation. Highly accessible features will influence decisions, while features of low accessibility will be largely ignored - and the correlation between accessibility and reflective judgments of relevance in a state of complete information is Id. not necessarily high.

227. Condlin, supra note 28 , at 270 (describing "nominalism about realism"). Ariel Rubinstein's review of Steve Levitt's once wildly popular book Freakonomics illustrates how common sense terminology can be used to do the work of social science jargon, and with a sense of humor. See Ariel Rubinstein, Freak-Freakonomics, THE ECONOMIST's VoICE, Nov. 2006, available at http://www.bepress.com/ev/vol3/iss9/art7. See also Gerd Gigerenzer, The Psychology of Good Judgment: Frequency Formats and Simple Algorithms, 16 MED. DECISION MAKING 273 (1996) (describing how medical patients make better predictions when problems are presented in the common sense language of frequencies rather than the technical language of probabilities). But see Prentice, Chicago Man, supra note 24, at 1702 ("[I]n the real world people often have to deal with problems presented as probabilities."); Id. at 1733-34 ("[A]s people go through life they will often be faced with problems framed as probabilities."). De-biasing seems to have the same "paired in the voting" relationship to anchoring that other pairs of Prospect Theory heuristics and biases have to one another. See Llewellyn, supra note 190 and accompanying text. Alter-ego concepts of this sort leave one where one started theoretically, although perhaps no worse for the wear. The problem, as Stanley Hoffman put it in another context, is that "Jargon has invaded everything and the relationship of theories to reality has faded." Craig Lambert, Le Professeur, 109 HARV. MAG. JulyAug. 2007, at 32, 37 .

264 
[Vol. 10: 2, 2010]

PEPPERDINE DISPUTE RESOLUTION LAW JOURNAL

of it all. Many examples could be given, but to avoid belaboring the point, I will limit myself to just one. It is said, on the basis of a meta-analysis ${ }^{228}$ of hundreds of anchoring studies, that bargainers may use anchors both "offensively" and "defensively.",229 In "playing offense ... negotiators who are aware of anchoring can - and should - use [this awareness] to their advantage in at least two ways." 230 They should "set high goals for themselves prior to the negotiation," table, they should "open with high demands (or low offers)... particularly ... when the opposing negotiator is relatively inexperienced ... and possess[es] relatively little information about the value of the item being negotiated."232 Negotiators who follow this advice, it is claimed, will "consistently outperform those who set more modest goals for themselves [because] high goal[s] ... anchor the negotiator's expectations about the outcome., 233

The point seems to be that bargainers should be ambitious, pursue ambitions diligently, and exploit ignorance and inexperience when they have the chance. ${ }^{234}$ This will not come as a shock to most lawyers. Few believe that low aspirations, half-hearted efforts in their behalf, and unilateral concessions to ignorance and inexperience are a formula for bargaining success. ${ }^{235}$ One might conclude, paraphrasing Horace, that "the mountain

228. Orr \& Guthrie, supra note 36, at 612-21 (describing the process of "conducting a metaanalysis"). Id. at 611 ("Meta-analysis can help ... overcome some of [the] methodological and interpretive difficulties" involved in working with individual studies that have "small sample sizes ... novice negotiators, and . . . simplistic fact patterns.").

229. Id. at 624 .

230. Id.

231. THOMPSON, supra note 97, at 47 ("“ $[\mathrm{N}]$ egotiators who set high aspirations end up with more of the pie than those who set lower aspirations."); accord Orr \& Guthrie, supra note 36, at 624,

232. Id. at $624-25$.

233. Id. at 624 .

234. Accord Korobkin, supra note 37, at 30-36 (presenting "reference point theory [of] . . how aspirations affect the outcome of settlement negotiations"); $i d$. at 56 (describing the "benefits of high aspirations"); THOMPSON, supra note 97, at 47 (same).

235. Professor Craver describes the conventional wisdom with characteristic clarity. See Charles B. Craver, Effective Legal Negotiation and Settlement 260 (5th ed. 2005) ("[P]eople who enter negotiations with high aspiration levels generally obtain more beneficial results than those who begin with less generous expectations. It thus behooves bargainers to commence their interactions with high demands or low offers.") (citation omitted). See also SHELl, supra note 31 , at 27-30 (describing the way in which aspirations influence bargaining outcomes).

265 
has labored mightily and brought forth a mouse.,"236 Legal commentators who offer advice of this sort typically do not say how high aspirations are developed or how high opening demands are made credible, even though these tasks are likely to prove more vexing to bargainers and are tasks in which help is more urgently needed. ${ }^{237}$ This is more than an academic point. By its very nature, Prospect Theory research has more to contribute to the improvement of bargaining skill than it does to the development of bargaining institutions and systems; ${ }^{238}$ in other words, it has more to say to

236. Quintus Horatius Flaccus (Horace), Ars Poetica [Epistle to the Pisos], in YALE BoOK OF QuOTATIONS 371, line 39 (Fred R. Shapiro ed., 2006). Perhaps it is just the juxtaposition of Orr and Guthrie's advice for bargainers to their summary of Prospect Theory research on anchoring that makes the advice seem so disappointing. When combined, the two "raise up a young boy's hopes [only to] crush them like so many paper beer cups... [and leave them like] ... popcorn for the pigeons beneath the 'L' tracks to eat." Steve Goodman, A Dying Cub Fan's Last Request, on AFFORDABLE ART (Red Pajamas Records 1983). Much the same could be said about legal bargaining theory's use of the Prospect Theory concept of framing. At one level, bargaining theory reduces the concept to the proposition that "how one thinks about an item will affect how one values it." Few would disagree with this, or be able to do much with it.

237. See SHELL, supra note 31, at 161 (Bargainers should open with "the highest (or lowest) number for which there is a supporting standard or argument enabling you to make a presentable case.") (emphasis omitted).

238. Trout makes one of the best arguments for using information about cognitive biases to create what he calls "institutional prosthetics" to aid decision making. Trout, supra note 48, at 414. $\mathrm{He}$ acknowledges that some will object to such a proposal on autonomy grounds, believing that "individuals should be permitted to simply choose a course of action, no matter how inferior that course of action is for the agent," but he denies that institutionally created de-biasing strategies would violate individual autonomy. Id. at 415 . Cognitive biases, he argues, "arise independently of the will [and] are ... external to it.... Therefore the protection sought from an institutional constraint focuses on something that is not the actor, a consequence that is not of an intended action." Id. at 416. He provides several examples of such constraints and describes how each would promote autonomy and enhance welfare. Id. at 425-33. See also Adler \& Posner, supra note 36, at S254 (Behavioral Decision Theory necessarily implies that "the market economy [should be replaced] with a system of pervasive government control, one that would prevent people from choosing and would instead force them to be happy."); Jolls \& Sunstein, supra note 48, at 206-24 (describing proposals for changing substantive law based on the insights of heuristics and biases research); Christine Jolls, Behavioral Law and Economics 18-34 (John M. Olin Center for Studies in Law, Economics, \& Public Policy Research Paper No. 342; Public Law \& Legal Theory Research Paper No. 130, 2006), available at http://papers.ssrn.com/sol3/papers.cfm?abstract id=959177 ("Illustrative Applications of Behavioral Law and Economics"); Jeffrey J. Rachlinski, The Uncertain Psychological Case for Paternalism, 97 Nw. U. L. REV. 1165, 1224 (2003) (“[G]overnments can adopt measures [based on research on bounded rationality] that restructure decisions as a less intrusive alternative to paternalistic restrictions on choice."); Rachlinksi, supra note 26, at 753-61 (describing applications of Behavioral Decision Theory to prevent or compensate for decision and judgment errors "in the Courtroom" and "outside of the Courtroom"); Stein, supra note 89, at 533 (describing structural changes which could be made to prevent "an autonomous person's bounded rationality ... [from taking] him down"); Mitchell, Why Law and Economics, supra note 33, at 13238 (describing "certain [political reforms] designed to serve a debiasing function ... without doing any harm to those unaffected by the bias or error."). Putting aside recommendations for changes in substantive law and legal institutions, it is misguided to change the incentive and constraint structure 266 
[Vol. 10: 2, 2010]

PEPPERDINE DISPUTE RESOLUTION LAW JOURNAL

practitioners, ${ }^{239}$ than to system designers and policy makers. Yet, if it is to be taken seriously by practitioners it must tell them something they do not already know. ${ }^{240}$ Recommending that they "buy low and sell high," in effect, does not do this. ${ }^{241}$ Anchoring is a complex and sophisticated phenomenon within Prospect Theory generally, but in the hands of legal bargaining theorists frequently it is stripped of this complexity and reduced to truisms. ${ }^{242}$

within which bargaining operates in order to compensate for the effects of heuristics and biases. It would conform system ideals to the limitations of bargainer skill, rather than ask bargainers to bring skill performance up to the level of system ideals. The former is a program for freezing the status quo, while the latter is one for improving it.

239. See Malhotra \& Bazerman, supra note 32, at 512-22 (describing how Behavioral Decision Theory insights can be converted into techniques for gaining influence in negotiation); Korobkin \& Guthrie, supra note 40, at 798 (describing "how negotiators can exploit heuristic reasoning on the part of others for personal gain"); $i d$. at 805 ("Negotiators who recognize that their counterparts are likely to rely on heuristics when making the types of judgments and choices commonly required in bargaining settings can use this knowledge to increase the likelihood of securing agreements on highly favorable terms.").

240. See Mitchell, supra note 24, at 1957 (“'Many studies in the judgment literature merely indicate whether a bias exists according to a particular statistical level of probability. This knowledge, however, is not adequate information for a practitioner deciding whether to be concerned about a bias."') (quoting Jay J.J. Christensen-Szalanski \& Cynthia Fobian Willham, The Hundsight Bias: A Meta-Analysis, 48 Organizational BehaV. \& Hum. Decision Processes 147, 149 (1991)). "Factors having small but statistically significant effects in the laboratory may pale in comparison to the force of other factors in real world settings." Id. at 1959.

241. Malhotra and Bazerman provide additional examples of this kind of advice. For example, among other things, they advise that: "[n]egotiators will be more likely to have an offer accepted when they have previously made an offer that was more extreme which was not accepted but which did not end the discussion." Malhotra \& Bazerman, supra note 32, at 518. Or, "[w]hen the issue being negotiated is of high importance to the other party, a negotiator will be more likely to have his or her offer accepted when strong rationales and justifications (e.g., appeals to higher authorities or strong norms) are presented early (rather than late) in the discussion." Id. at 521. Or:

A negotiator who has strong justifications and arguments will be more likely to have his

or her demands accepted if he or she (a) speaks slowly, (b) avoids being overly technical,

(c) provides a written explanation of the core demands and justifications, and (d) avoids negotiating at a time when the other party is distracted.

Id. at 522. Malhotra and Bazerman also advise bargainers to "familiarize themselves with the tactics that may be used against them and actively discount their desire to comply," and suggest "that wellprepared negotiators are less likely than ill-prepared negotiators to be influenced by the (psychological) influence attempts of the other side." Id. at 523, 524.

242. This would not be the first time a complicated social scientific concept was trivialized by overuse. Compare the treatment accorded Thomas Kuhn's well known concept of paradigm. See Jeff Sharlet, A Philosopher's Call to End All Paradigms, CHRONICLES OF HigHER EDUC., Sept. 15, 2000, at A18 (discussing Thomas S. Kuhn, The Structure of SCientific Revolutions (2d ed. 1970), and the many ways in which the concept of "paradigm" was misunderstood and misused). 
Incorporating the insights of anchoring research into legal bargaining theory is no doubt worth the effort, but first several preliminary questions must be answered. The most fundamental of these questions asks how a number becomes an anchor. Is an anchor simply the first number mentioned in a bargaining conversation-no matter how inflated, frivolous, or laughable - or the first number to be validated by some sort of testing process? If it is the latter, is an anchor number the winner of a contest between the parties' competing substantive arguments and leveraging moves, existing in an oscillating suspension between both sides' claims until one side convinces or silences the other? If so, are the advocacy moves made in support of an anchor number more important determinants of bargaining outcome than the number itself, or are advocacy moves and anchor numbers so intertwined that they cannot be discussed separately? Alternatively, is an anchor number just another substantive data point, part of the body of relevant information a rational bargainer should take into account in determining what to think? Is being influenced by an anchor no more than considering all relevant evidence before deciding how to proceed? Ultimately, I expect that questions about how to defend and test anchor numbers will be more important inquiries for legal bargaining theorists than questions of how to identify anchor numbers in the first instance. ${ }^{243}$ They may be the same questions.

The so-called take-away lessons in anchoring scholarship, at least as presently advanced by legal bargaining scholars, seem to be these: think carefully before making and acceding to demands, avoid impulsive, thoughtless, careless, and reckless choices, take all relevant perspectives into account, draw on precedent, analogy, objective standards and relevant evidence in supporting demands and claims, and always begin by asking for a lot more than you hope to end up with. None of these lessons are controversial or counterintuitive. In fact, they are the central lessons of traditional legal bargaining theory. The only surprising thing is that some legal bargaining theorists repeat them under the guise of providing new insight from social science research. It is like telling an adult to look both ways before crossing the street. No doubt, there are instances in which such

243. Orr and Guthrie may disagree with this focus. Though they recommend the adoption of both "inside strategies" (those that require individual bargainers to test and evaluate anchor numbers for themselves) and "outside strategies" (those that change the incentive or constraint structures within which bargaining operates), for minimizing the impact of anchor numbers, they seem to prefer the latter. See generally Orr \& Guthrie, supra note 36, at 625-27. Yet, changes in the incentive and constraint structures of bargaining are likely to change only the nature of bargainer strategies and tactics. Skilled bargainers will adapt quickly to any new structural framework in which they find themselves and learn to manipulate adversaries within it. 268 
[Vol. 10: 2, 2010]

PEPPERDINE DISPUTE RESOLUTION LAW JOURNAL

advice would help but most of the time it is not likely to have much of an instructional effect.

\section{RESEARCH ON LEGAL BARGAINING}

Most social science research on legal bargaining is based on questionnaires asking lawyers how they bargain, ${ }^{244}$ or hypothetical decision scenarios asking college students (and others) to resolve bargaining judgment problems, ${ }^{245}$ and for different reasons neither data set is completely representative of legal bargaining practice. Lawyers do not always bargain as they say or think they do; frequently their reports are selftribute and self-deception more than self-description, shaped by hopes, expectations, assumptions, and beliefs more than behavioral observations. ${ }^{246}$

244. Condlin, supra note 28, at 278-92 (describing survey research on lawyer bargaining, including the Williams Study, the Schneider Study, and the Macfarlane Study).

245. Korobkin, Aspirations, supra note 37, at 36-37 (describing an experiment in which law students were asked questions about how they would act in hypothetical bargaining decision scenarios).

246. Condlin, supra note 28, at 282-89 (describing the difficulties involved in interpreting lawyer self-descriptions of bargaining behavior). This is not to say that questionnaire research is never useful. For an interesting illustration of how it could be, consider a variation on the Guthrie/Rachlinski experiment with insurance industry professionals. See Guthrie \& Rachlinski, supra note 40, at 2023-33. Guthrie and Rachlinksi distributed questionnaires to insurers and reinsurers (in two different studies), asking for settlement recommendations in two hypothetical personal injury cases. Id. at 2025. Among other things, the questionnaires were designed to explore whether sophisticated repeat players and stakeholders in the settlement process "have ... cognitive skills that enable them to avoid many common errors in judgment that appear to plague other actors." Id. at 2022. The results were mixed. The first iteration of the experiment (with insurers), found that policy-limits information provided in the hypothetical problems "operated as an anchor" to increase the recommended awards significantly. $I d$. at 2030. However, the second iteration (with reinsurers), found "that the [subjects] resisted the influence of anchoring on their judgments." Id. at 2032. Guthrie and Rachlinski speculate about reasons for the different results, but they did not ask the subjects themselves for an explanation. Id. at 2032-33. This is not surprising since they were interested in how insurance professionals would resolve the problems, not why they would resolve them in a particular way. For those interested in explaining the different effects of policy-limits information in the two experiments, however, the subjects' mental states could provide important additional data. The subjects might know something not evident in their behavior-about norms, stereotypes, biases, assumptions, or other factors associated with their conceptions of professional role, station, duties, loyalties, and the like - that would help explain why policy limits were more of a concern to insurers than reinsurers. Asking them to go inside themselves, so to speak, and report on such information makes at least as much sense as asking them to step outside themselves and describe their bargaining behavior (as most questionnaire research on lawyer bargaining does). This does not mean that their explanations necessarily would be correct. The explanations would be only data, after all, and the subjects could have all kinds of reasons to dissemble, mislead, or exaggerate. 269 
And while patterns in the way college students solve problems is direct observational data and thus free from the biases of self-reporting, these patterns do not reflect the professional socialization and real life practical constraints that make academic game playing unlike real life legal bargaining. Social science research subjects live in their own distinctive world of social practices, institutional contexts, and conversational conventions, and while they may bargain in that world, they do not do so in the same way that lawyers do in theirs. Thus, for different reasons, much of the social science research underlying the new legal bargaining theory provides an as yet unproven foundation for prescriptive advice.

Optimally, the study of legal bargaining should be based on observation of actual legal negotiations conducted in offices, boardrooms, courtroom corridors, and the other various places where legal disputes are settled. ${ }^{247}$ Data of this sort would eliminate debates over the question of how lawyers bargain and permit scholars to focus on the more interesting questions of what types of bargaining behavior work and under what circumstances. Most bargaining scholars do not work with such data because it is nearly impossible to collect. Clients and lawyers would have to agree to record their negotiations, for one thing, and most will not do this. Information shared in bargaining may or may not be privileged, ${ }^{248}$ but it is at least private

They also could be mistaken, or just not know why they acted as they did. But in a circumstance like this, questionnaires that ask about mental states can supplement questionnaires that ask about behavior, and produce useful additional information in the process. See, e.g., ARGYRIS \& SCHÖN, supra note 101, at 38-42 (describing method for collecting data about mental states and illustrating how it can be used to supplement observed behavior). But see generally Richard E. Nisbett \& Timothy Decamp Wilson, Telling More Than We Can Know: Verbal Reports of Mental Processes, 84 PSYCHOL. REV. 231, 231-32 (1977) (arguing that asking subjects to report their mental processes does not always produce accurate and reliable data).

247. Mitchell, Why Law and Economics, supra note 33, at 127-32 (recommending research based on "contextualized accounts of behavior," using "experiments and simulations, survey and interview research, field studies or observational studies, and nonreactive studies.") (citation omitted). Research of this sort is qualitative rather than quantitative, and asks how the bargaining process works rather than whether it works. Cf. Tom Baker \& Sean J. Griffith, How the Merits Matter: Directors' and Officers' Insurance and Securities Settlements, 157 U. PA. L. REV. 755, 759761 (2009) (describing the use of qualitative research methods to study settlement practices in securities class action litigation).

248. Rule 408 of the Federal Rules of Evidence and its state law analogues are the principal regulations governing the availability in discovery of information disclosed during settlement negotiations. For discussions of these rules, see Jane Michaels, Rule 408: A Litigation Mine Field, 19 Litig. 34, Fall 1992; Wayne D. Brazil, Protecting the Confidentiality of Settlement Negotiations, 39 Hastings L.J. 955 (1988); Russell Korobkin, The Role of Law in Settlement, in THE HANDBOOK of Dispute Resolution 254 (Michael L. Moffitt \& Robert C. Bordone eds., 2005). Private information disclosed in negotiation also can be regulated by contract though confidentiality agreements between the parties, even though there are many policy objections to such agreements and state laws often preclude them. See Carrie Menkel-Meadow, Public Access to Private Settlements: Conflicting Legal Policies, 11 Alternatives High Cost OF Litig. 85 (1993); Laurie 270 
[Vol. 10: 2, 2010]

PEPPERDINE DISPUTE RESOLUTION LAW JOURNAL

and in most instances there is no reason clients would want to make it public. Lawyers also will be reluctant to reveal the distinctive strategies they think give them an advantage in bargaining, though both the distinction and the advantage are easily overestimated. Even if these obstacles could be overcome, studying bargaining on-site, in all of its multiple dimensions, ${ }^{249}$ is the work of anthropologists more than legal scholars and anthropological methods are slow, time-consuming, and expensive. Perhaps more importantly, they do not produce the kind of easily quantified and sorted data with which the new legal bargaining theorists like to work. There are a few interesting anthropological studies of legal bargaining, ${ }^{250}$ but they are likely to remain the exception for some time to come.

If data about real life negotiation is not usually an option, recordings and transcripts of sophisticated laboratory simulations often are the next best alternative. ${ }^{251}$ To be useful, however, such simulations should be conducted spontaneously, and not according to scripts, by practitioners experienced in the matters being negotiated who are working with actual case materials (documents, physical evidence, live witnesses, and the like) under realistic time constraints and in authentic practice settings. ${ }^{252}$ Of course, no

Kratky Doré, Secrecy by Consent: The Use and Limits of Confidentiality in the Pursuit of Settlement, 74 Notre DAME L. ReV. 283 (1999).

249. See David A. Lax \& James K. Sebenius, 3-D Negotiation:Powerful tools to Change The Game IN Your Most Important Deals 7-19 (2006) (describing the multiple dimensions of deal making negotiation and the 3-D focus).

250. The studies illustrate the difficulty of collecting real life data as much as they demonstrate its availability. Jonathan Harr's study of the Woburn leukemia cluster litigation is perhaps the best example. Harr spent several years imbedded with the plaintiff's legal team in order to write the story of the litigation, including its complicated settlement proceedings. See Jonathan Harr, A CiviL ACtion (1996). Other such studies include Peter H. SCHUCK, Agent Orange on Trial: Mass TOXic Disasters in the Courts (1986); Gerald M. Stern, THe Buffalo CreeK DisAster: The STORY OF THE SURVIVORS' UNPRECEDENTED LAWSUIT (1976, reissued 2008); and JeFFREY W. Stempel, Litigation RoAd: THE Story of CAMPBELL V. STATE FARM (2008). Sometimes nonanthropological studies are described as based on real life negotiations. See, e.g., Rachlinksi, supra note 37, at 149 (describing the Gross-Syverud California litigation study, as "analyzing unsuccessful settlement talks") (citing Samuel R. Gross \& Kent D. Syverud, Getting to No: A Study of Settlement Negotiations and the Selection of Cases for Trial, 90 MiCH. L. REv. 319 (1991)). But usually these studies are based on numerical data taken from real life negotiation rather than on direct observational data of the negotiations themselves. See Gross \& Syverud, supra, at 330-79 (comparing final settlement offers available in a verdict reporting service with the results at trial in the same cases).

251. Prentice, Chicago Man, supra note 24, at 1751 (“[A]s a general rule, 'real world' behavior is very similar to laboratory behavior.").

252. See Condlin, Bargaining with a Hugger, supra note 92, at 16-20 (describing a negotiation simulation with such qualities as case materials and real life circumstances). Professor Minzner 271 
simulation can reproduce the conditions of real life bargaining perfectly. It is virtually impossible to replicate in a laboratory the social relationships, interpersonal histories, institutional restrictions, practical incentives and constraints, affective states, ${ }^{253}$ and working conditions of real life bargaining. But sophisticated simulations can generate trustworthy data about bargaining technique and the moves and maneuvers lawyers use to influence one another in the "at the table" part of the bargaining process. Scholars in turn can use that data to analyze the ways in which such technique influences bargaining outcome. ${ }^{254}$

Data from simulated bargaining might also be used to test the trustworthiness of other empirical research on legal bargaining. Much of this other research, as I indicated earlier, is based on survey research asking lawyers to describe their bargaining behavior (and that of their adversaries) and to evaluate its effectiveness, all as part of a single undifferentiated inquiry. ${ }^{255}$ This is a less useful inquiry than it may at first appear, since it permits respondents to commingle judgments about effectiveness with descriptions of behavior (and vice versa), jeopardizing the accuracy of each. $^{256}$ For example, lawyers are likely to believe that they use and are influenced only by strategies and tactics that are sociable and skillful, and that threat, belligerence, rudeness, irrational argument, excessive demand and the like have no place in their bargaining styles or influence over their bargaining decisions. When they report on past bargaining experiences, therefore, they are likely to remember and describe the experiences in this

describes the benefits of adding such contextual information to social science experimentation. See Minzner, supra note 77, at 2567-71.

253. Mitchell, Why Law and Economics, supra note 33, at 104 (questioning whether the "relatively dispassionate written summaries of cases . . . so often used in ... negotiation simulation studies do justice to the emotions elicited by a real case involving real lives or real pocketbooks").

254. Prospect Theory research contributes little to the analysis of bargaining skill since most of its experiments leave little or no room for skill to operate. See discussion supra. For a description of the full set of "at the table" skills, particularly in deal making negotiation, see LAX \& SEBENIUS, supra note 249 (overview of the different aspects of deal making negotiation).

255. See Condlin, supra note 28, at 278-81 (describing some of the confusions in survey research on bargaining through a discussion of the Williams Study).

256. See id. at 281-82 (describing how the two types of judgments can intertwine). It is not surprising that the two types of judgments would be commingled in lawyer reports about their bargaining behavior. Descriptions of how one bargained, and descriptions of whether that bargaining was effective, are two sides of the same coin. For example, if a demand is seen as greedy, it is only natural to think that it also is ineffective, for just that reason. But if the offended bargainer is unduly stingy, it would be a mistake for the other bargainer to conclude that he needed to temper his demands. Generalizing from a single experience is warranted only when the experience is representative. Even if a generalization is warranted, an adversary's view about effectiveness is not always the best evidence of whether a particular move worked. Excessive demands sometimes produce better settlements than reasonable ones whether the other bargainer is aware of it or not.

272 
[Vol. 10: 2, 2010]

PEPPERDINE DISPUTE RESOLUTION LAW JOURNAL

way. Since most bargaining behavior can be characterized in a wide variety of ways depending upon one's perspective, seeing it in unqualifiedly positive terms (or negative if it is the adversary's behavior) is not difficult. A perceived threat in the eyes of one bargainer easily can be seen as unwarranted paranoia in the eyes of another; belligerence in the eyes of one might be squeamishness in the eyes of another; an excessive demand in the eyes of one might be a reasonable request in the eyes of another, and so on and so forth. There are few fixed limits on making characterizations of this sort.

In analyzing lawyers' responses to survey research questions, therefore, it often is difficult to determine whether the lawyers' descriptions of how they bargained are self-interested and unreliable, or whether the lawyers were able to step outside their narrow, personal perspectives and describe their behavior accurately. Did the lawyers identify (or even know) their actual reasons for settling, for example, or did they give accounts based on what they thought were the most skillful ways to behave? Did they produce personal hagiographies of their bargaining past, in other words, or accurate historical reconstructions? Empirical research on legal bargaining must resolve these and other such concerns before it can construct a realistic picture of lawyer bargaining practice. Laboratory simulation, which records, transcribes, and analyzes data independently of the participants' views about what happened, separates the task of describing bargaining behavior from the task of evaluating its effectiveness and thus holds greater promise for constructing such a picture.

\section{CONCLUSION}

By any standard, Prospect Theory research has made important contributions to the understanding of human decision making and judgment. In its criticism of the factual assumptions of the rational-choice model and its construction of an intuitively attractive and intellectually powerful alternative, it has raised major questions about the relevance and accuracy of a good deal of empirical legal scholarship. In a virtuoso fusion of science and psychology it has begun to create a scientific psychology for a post rational-choice age. ${ }^{257}$ Impressive as this accomplishment is, it does not

257. Jeffrey Rachlinski makes perhaps the most hopeful prediction for Behavioral Decision Theory generally. See Rachlinski, supra note 26, at 766 .

Economics provided law with a behavioral theory that is rigorous and precise, but lacks 273

an empirical foundation. Psychology offers an empirical, scientific source for theories of 
follow that Prospect Theory has equivalent implications for legal bargaining theory. Decision making in bargaining is different from decision making in general, and the experimental data on which Prospect Theory is based does not yet take these differences into account. As a consequence, many of the most ambitious proposals for reshaping legal bargaining theory along Prospect Theory lines are as yet unsupported by Prospect Theory findings, and the less ambitious proposals do not need a Prospect Theory pedigree. Legal bargaining theorists should continue their efforts to make bargaining scholarship more empirical, of course, since bargaining is an empirical practice. And they also should draw on social science research whenever possible in this effort since law, at least in part, is a social science. But they should approach these tasks as skeptical critics, not already committed disciples, prepared to test, modify, and refine social science insights before using them to modify legal bargaining theory. If, as an eminent scholar once told me, all viable theory overlaps by sixty percent, that still leaves a lot of room for irrelevance.

human behavior. We have only begun to see how the scientific study of human behavior will reshape the study of law. The new law and psychology is just now cutting its teeth. ... The best work, however, is yet to be done. 